\title{
Comparative Study of Energy Absorption Capability of Flat Plate Coupons Made by CFRP Plain Weave Fabric Composites
}

\author{
Redouane Lombarkia1*, Augustin Gakwaya1, Denis Nandlall2, Marie-Laure Dano1, \\ Julie Lévesque', Ameur BenKhelifa1', Philippe Vachon-Joannette' ${ }^{1}$, Philippe Gagnon ${ }^{1}$ \\ ${ }^{1}$ Department of Mechanical Engineering, Université Laval, Québec, Canada \\ ${ }^{2}$ Canada Defence Research \& Development Canada, Valcartier, Québec, Canada \\ Email: ${ }^{\star}$ Redouane.lombarkia.1@ulaval.ca
}

How to cite this paper: Lombarkia, R., Gakwaya, A., Nandlall, D., Dano, M.-L., Lévesque, J., BenKhelifa, A., Vachon-Joannette, P. and Gagnon, P. (2021) Comparative Study of Energy Absorption Capability of Flat Plate Coupons Made by CFRP Plain Weave Fabric Composites. World Journal of Mechanics, 11, 121-145.

https://doi.org/10.4236/wjm.2021.117010

Received: May 4, 2021

Accepted: July 4, 2021

Published: July 7, 2021

Copyright $\odot 2021$ by author(s) and Scientific Research Publishing Inc. This work is licensed under the Creative Commons Attribution International License (CC BY 4.0).

http://creativecommons.org/licenses/by/4.0/

\begin{abstract}
Despite years of governmental and academic institutions' researches, no experimental standards are established for evaluating crush Specific Energy Absorption SEA for plain weave fabric woven carbon-fiber-reinforced composites used in modern aircraft structures as elements of the boxes to mitigate damage during crush events. At the laboratory scale, this paper proposes a comparative study of energy absorption capability of flat plate coupons made by CFRP plain weave fabric composites. A new fixture design and setup were created with hydraulic pressure and drop tower machines to carry out tests of flat plate composite specimens under quasi-static and low velocity on-axis crash loading. For investigating parameters sensibility of triggers and layups, numerical and experimental results of four trigger types and three stacking sequences were compared. A confrontation between experimental and predeveloped UL-Crush numerical material model results confirms that coupons with $0^{\circ}$ oriented central plies and saw teeth or corrugated triggers dissipates higher energy during crush, compared to coupons with $90^{\circ}$ or $45^{\circ}$ oriented central plies and chamfer $45^{\circ}$ or steeple triggers. An efficient and simplified experimental methodology was developed to measure and investigate different parameters influencing SEA of composites under crush load. Comparison between experimental and UL-Crush material model confirms the performance of such simulation tool.
\end{abstract}

\section{Keywords}

Crush Behavior, Triggers, Damage and Failure Mechanisms, Crashworthiness, SEA 


\section{Introduction}

Structural energy absorbers can be found in all modern vehicles in the form of collapsible floor stanchions and beams in aircraft subfloor and cargo structures [1], and in the form of collapsible tubular rails in the front end of passenger cars. FAA (Federal Aviation Administration) issued Advisory Circular AC 20-107B "composite aircraft structure" based on the researches on composite aircraft structures involving fiber-reinforced materials. The FAA requires an assessment of each new aircraft design regarding crashworthiness performance, i.e. its ability to protect its occupants during a crash event.

Aircraft manufacturers are currently using numerical simulations in the process of designing, testing, and certifying aircraft parts such as seats, wings.... following the building block approach as shown in Figure 1.

With the advancement made in computing technologies, Finite Element simulations have become an important tool to predict crush behavior by using high performance material models, [3]. Modeling aircraft components crush response is already involved in different explicit nonlinear dynamic finite element codes such as ABAQUS, PAM-CRASH, LS-DYNA, DYNA3D, and MSC. Dytran, [4].

Virtual testing should consider various aspects:

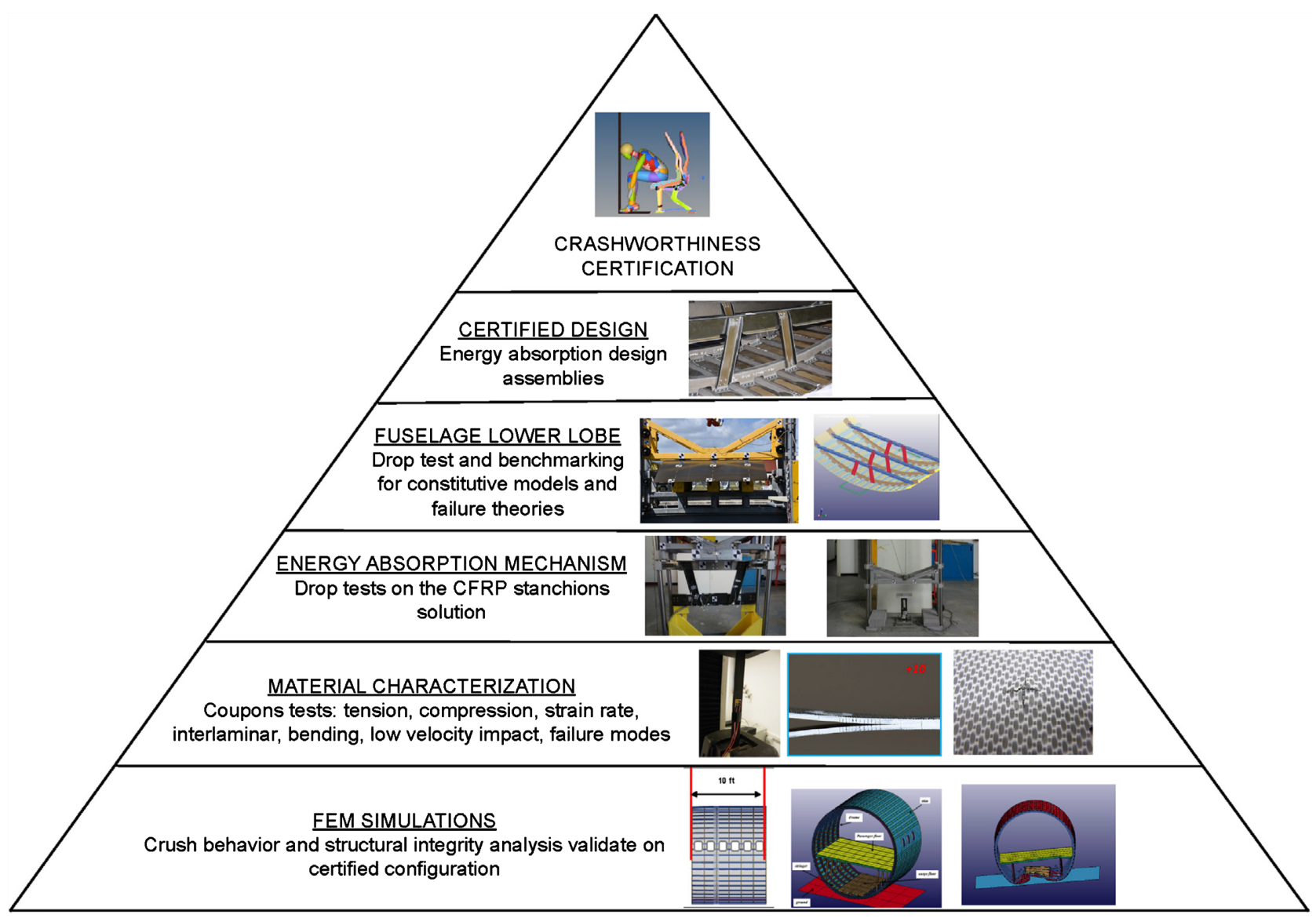

Figure 1. Building block approach [2]. 
1) A precise comprehension of the scenario of crush in term of damage mechanisms sequence,

2) Appropriate representation of each damage mechanism in form of criterions within constitutive and kinematic laws of the material,

3) Identification of each parameter with the continuous improvements of the measurement and inspection techniques [5] [6], and validation of the developed computational tools [7].

To assist predictive simulation tools for crush of composite parts, more fundamental experimental test methods are needed for model validation, other specific experiments are also necessary for identification of the different input parameters of the crush material model.

Compressive failure mode is complex as it involves several interacting failure mechanisms, such as micro buckling, kink-bandings, fragmentation and delamination. Furthermore, the material response can be sensitive to fabrication defects and imperfections. In general, predicting the response of structures subjected to severe compressive loads is even more challenging than predicting their tensile response [8].

Crush load as compressive load is complex and some factors contributing to this complexity have been identified: a) the large strains and rotations involved; b) the interaction of complex damage mechanisms; c) significant geometric transformations in the crushing zone; d) material nonlinearity; e) contact and friction and $f$ ) potential strain rate effects [9].

Crush behavior of composite materials has been observed to depend on a large number of factors such as the trigger types, the scale and cross section of coupons, the layups and the fiber architecture [10] [11] [12] [13] [14].

In order to compare crush behavior of materials, most authors use the SEA calculation as a main metric evaluated from crush tests. Unfortunately, there is no standardized test method for assessing the SEA coefficient, and research efforts can not be directly compared because different test methods are used in several works. However, some efforts are being made by the Crashworthiness Working Group of the CMH-17 [15], with the ASTM International Committee D-30 in order to arrive at establishing some standards. Similarly, the Energy Management Working Group of the ACC [16], government organizations such as the US National Aeronautics and Space Administration (NASA) [17], the German Aerospace Center (DLR) [18], and the National Aerospace Laboratory of the Netherlands (NLR) [19], have also dedicated resources aimed at the set up of standard experimental characterization process of composite crush energy absorption [1]. Usually, thin-walled tubular specimens rather than flat coupons or other shapes have been used for SEA measurements and crush energy investigations. Tubes were selected because they are self-supporting and therefore do not require special fixtures, and they are commonly used in automotive crush structures. Some of the observed results reported by authors are contradictory and questions remain how exactly certain parameters influence results [1]. 
To avoid complicated coupling between such factors, in the aim of characterising material parameters, validating constitutive material model and SEA measurement, an alternative approach is then to use a flat plate material coupon, with the advantage of being easily manufactured with no requirement for special tooling. However, anti-buckling fixture for supporting the flat coupon without inducing friction or suppressing crush failure and preventing catastrophic failure is often required [20] Figure 2.

Several other anti-buckling fixtures for flat coupons crush testing have been proposed over the years, and a good review is provided by [1] Figure 3 .

Such fixtures require an unsupported height at the crush front where material bend and form fronds, and debris are evacuated.

The free unsupported height of specimens may influence the precision of the calculated SEA and crushing stress. An optimised free height has been found to be compromised between $(3.2-12.8 \mathrm{~mm})$ for SEA measurements and between (10 - $25 \mathrm{~mm}$ ) for crushing stress measurements [1].

Other fixtures for flat coupons have also often been adopted with no anti-buckling system by minimizing the free unsupported height of specimens to capture necessary crush behavior; force peak and sustainable post peak load, Figure 4 .

Many Researches works confirms that the modulus and strength of composites increases with strain rate and that the dependency on the strain rate is

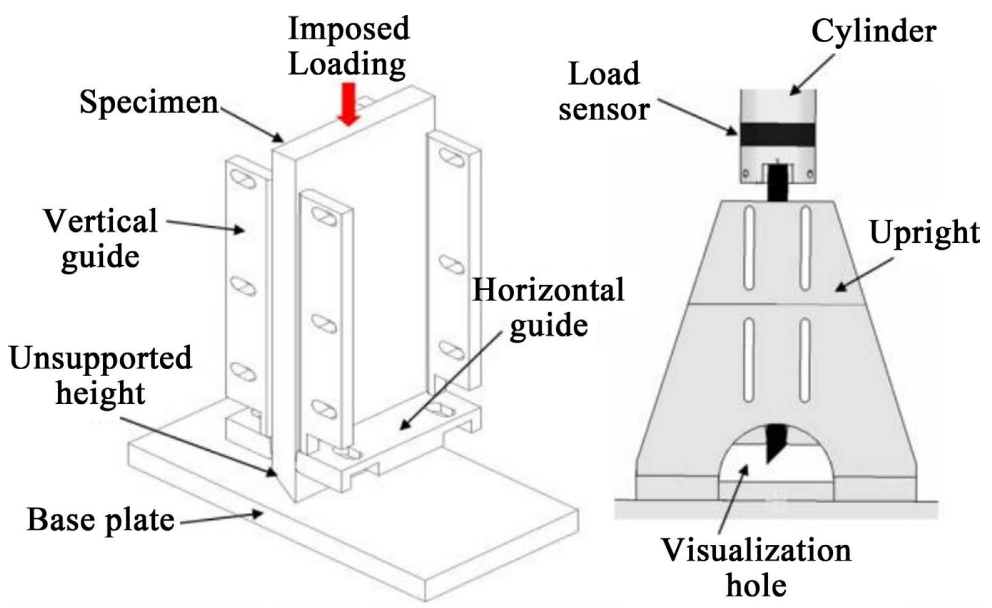

Figure 2. Flat coupon crush test fixture from [20].

(a)

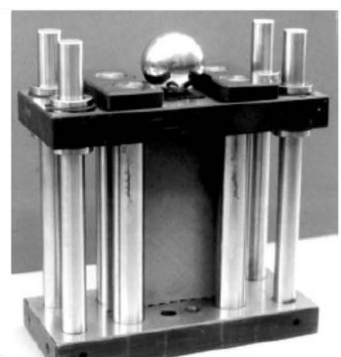

Figure 3. Flat coupon crush test fixtures from (a) NASA, [17]; (b) Engenuity, [15]; (c) Oakridge National Laboratory [19].

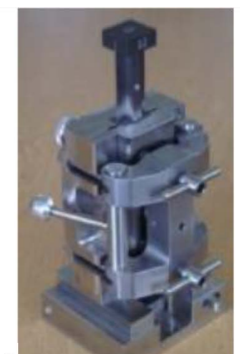

(b)

(c)

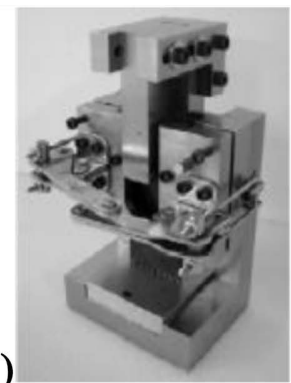




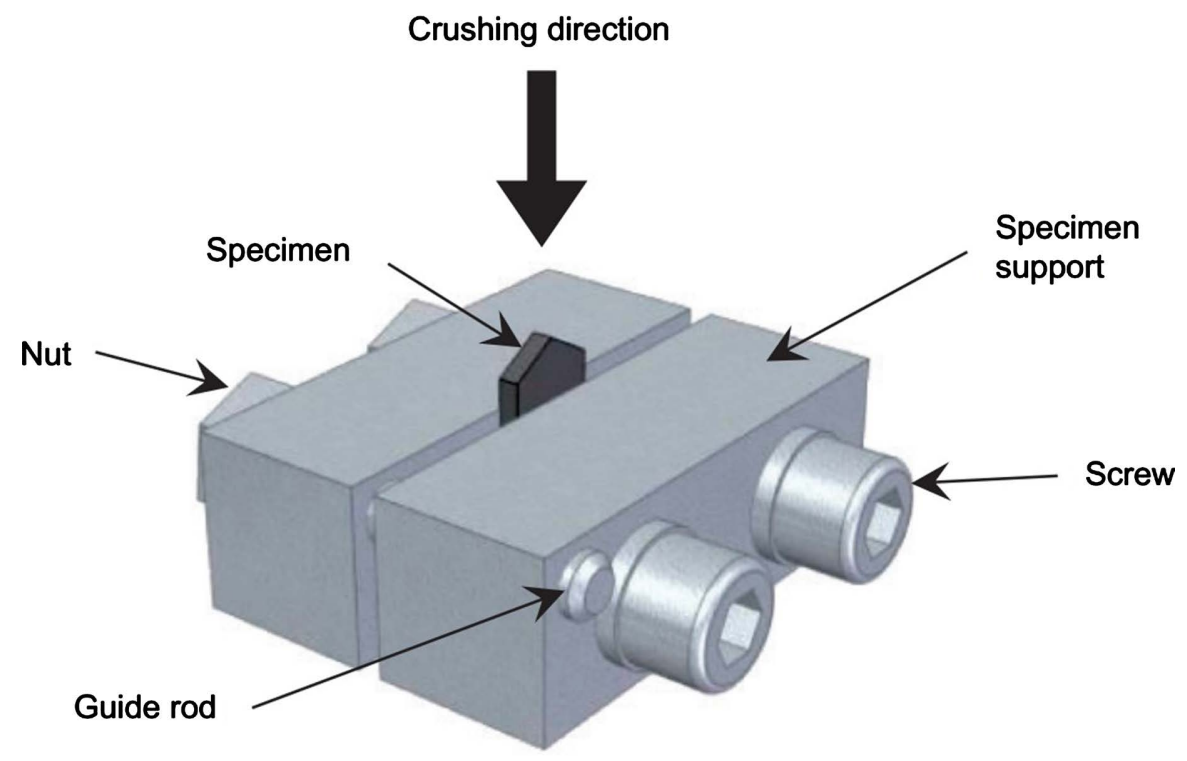

Figure 4. Flat coupon crush test fixtures from [21].

driven by matrix material [3].

Matrix semi-crystalline thermoplastic resins (such as polycarbonate) offer advantages compared to conventional thermosetting resins (such as epoxies); and these includes better chemical resistance, temperature resistance and impact resistances, and they may be used for aircraft applications.

In order to test different crash scenarios under different strain rates, various test machines are utilized:

For quasi-static tests, from $10^{-2}$ to $10^{-3} \mathrm{~s}^{-1}$, simple hydraulic pressure machine can be used with different fixture systems.

For low velocity tests, with strain rates ranging from 1 to $10^{2} \mathrm{~s}^{-1}$, specialized machines such as drop towers (e.g. Instron 9340) should be utilized for measuring the impact energy absorption capacity as well as the damage initiation and propagation [22]. Used a modified off-axis compression fixture set-up to carry out tests on carbon fiber reinforced coupons under quasi-static and low velocity compression by using an MTS Criterion series40 Loading frame and drop tower facility.

For high velocity tests, with strain rates ranging from $10^{2}$ to $10^{4} \mathrm{~s}^{-1}$, experiments can be achieved using a split Hopkinson pressure bar [23], such tests require the use of high-speed videography [24].

For very high velocity tests, with strain rates ranging from $10^{4}$ to $10^{6} \mathrm{~s}^{-1}$, experiments can be achieved using the acceleration of projectiles or the detonation of explosives [25].

The scope of the present work is limited to damage occurring in compression for quasi-static and low velocity compression tests with strain rates ranging from $10^{-2}$ to $10^{2} \mathrm{~s}^{-1}$.

The originality of this paper concerns the establishment of a simple experimental method and design of setup and fixture to be installed within a drop 
tower to perform crush tests of small flat plate composites coupons in the aim of investigating the QS and dynamic responses during crush loading.

Hence, a comparative study is conducted to evaluate the influence of the trigger geometry, layups and strain rates on the crushing response by selecting four trigger types, three layups and two strain rates.

For in plane crushing, the objectives are: 1) to observe how triggers can improve coupons stability during the crushing process, and 2) how damage mechanisms, such as fragmentation, delamination and kink bandings can be exploited to achieve a high amount of absorbed compressive energy.

Moreover, the boundary conditions of the tests and the damage growth observed from video recordings and microscopic inspections will be discussed.

Twenty-four CFRP plain weave fabric composite flat plate coupons were carried out with variations in stacking sequences, strain rates and trigger types, using new setups, multiple measurements and inspection instrumentations for a better damage mechanisms and energy absorption investigation, providing relevant guidelines to identify future research directions. The plan of the paper is as follows:

Section 2 deals with the experimental procedures and coupons preparation. Section 3 provides a presentation of experimental results while Section 4 gives a general presentation of the numerical simulation and pre-developed material constitutive model. In Section 5, a discussion about experimental results and a comparison between numerical and experimental results are presented, and finally, section 6 gives conclusion.

\section{Experimental Work}

The first goal of the experimental work is the investigation of the energy absorbing capability of flat plate coupons made from plain weave fabric composite in order to validate numerical modeling methodology following Building Block Approach. A systematic experimental investigation is conducted to evaluate the influence of the trigger geometries, layups and strain rates on the crushing response. Quasi-static and dynamic crush experiments in which one parameter is tested while keeping all other testing parameters constant are carried out. From the obtained results, the best material configuration to achieve more energy dissipation will be established.

The material system selected for this study is plain weave (PW) fabric carbon fiber/epoxy prepreg supplied by Bell Helicopter Textron Company (BHTC). Such material is used extensively for general aviation primary structures.

1) Machine of tests and instrumentations

For quasi-static tests, the MTS Criterion Series 40 universal machine is used with setup and fixture as shown in Figure 7.

For low velocity crush tests, the test system, Figure 5, is formed of drop tower CEAST Instron9340 and setup with fixture installed within the inferior enclosure of the drop tower. Composite flat plate coupon is clamped at the end of the 
fixture fixed into the setup. A metal mass (net weight of $22.5 \mathrm{~kg}$ ) is added to achieve the necessary crushing energy. An impactor of diameter $22.5 \mathrm{~mm}$ translates along $\mathrm{Z}$ vertical axis to transmit load to the setup and to the coupon.

The used setup, Figure 6, has been designed and manufactured within the

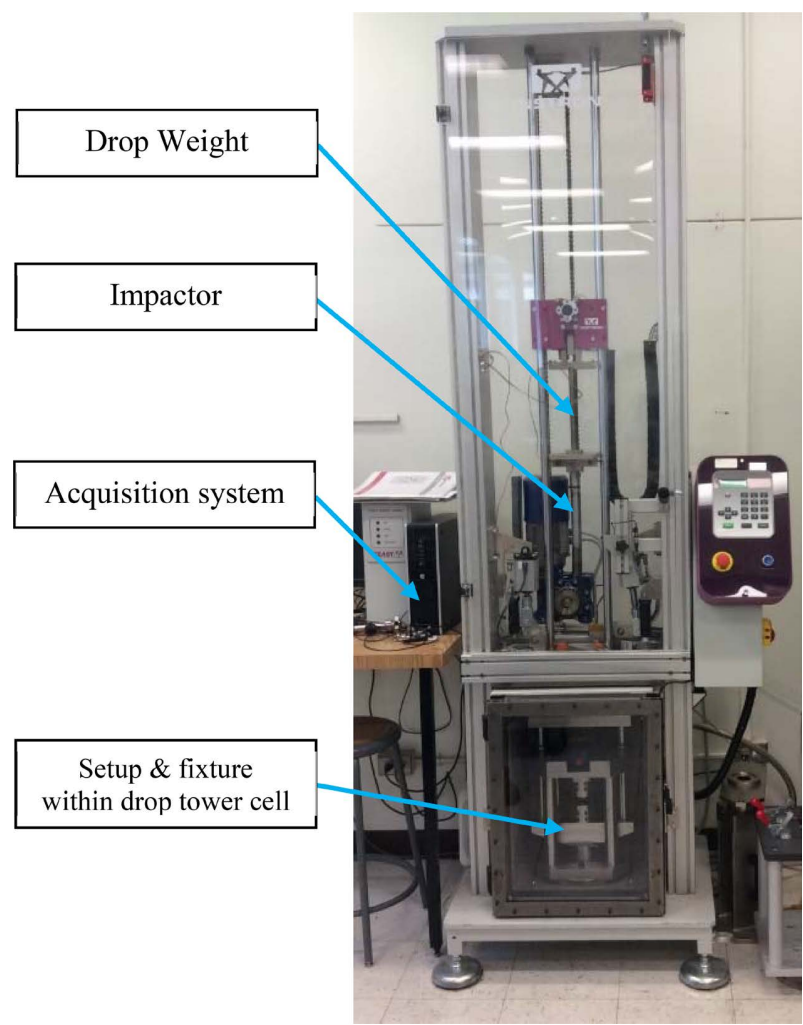

Figure 5. Drop Tower CEAST Instron9340 with developed setup and fixture.

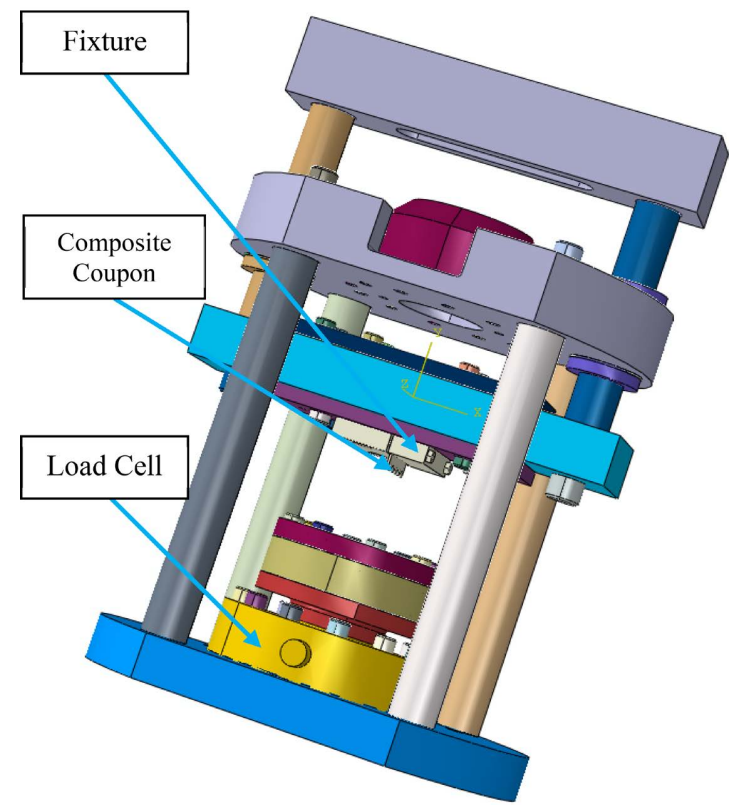

Figure 6. Setup for QS and Dynamic crush tests to insert into enclosure Cell of drop tower. 
M3C Laboratory (Mechanical Engineering Department of Université Laval). It is composed of two fixed plates and two vertical translational plates, and an M1404 Series PCB piezo electrical Load Cell has been added at the bottom of setup to capture crush forces.

Different fixtures may be added to clamp different geometries of composite coupons. A fast Camera, GOM Aramis Digital Image Correlation DIC and video extensometer have also been added to measure displacement of specimens,

2) Tests campaigns

Two different test campaigns were performed to collect data:

- The $1^{\text {st }}$ session of tests with flat plate specimens were concerned with QS crush tests using the MTS Criterion series 40 machine, Figure 7, with the new setup and fixture.

- The $2^{\text {nd }}$ session of tests were carried out with Instron9340 drop tower with new setup and fixture for low velocity crushing.

The composite material adopted in this study is CFRP, especially prepared for the CRIAQ Comp-410 project, which is a research project in partnership with Bombardier and BHTC. The material used is a plain weave PW woven-ply Carbon fiber reinforced epoxy thermoset matrix. Fabric is constructed from yarns in which fibers are bundled or twisted into threads. The density is $1527 \mathrm{Kg} / \mathrm{m}^{3}$. Each Composite ply should have a thickness of $0.203 \mathrm{~mm}$. The required plies number of plain fabrics is eight.

The standards for characterization tests were developed for composite materials with unidirectional architecture. No standard exists to date for composite

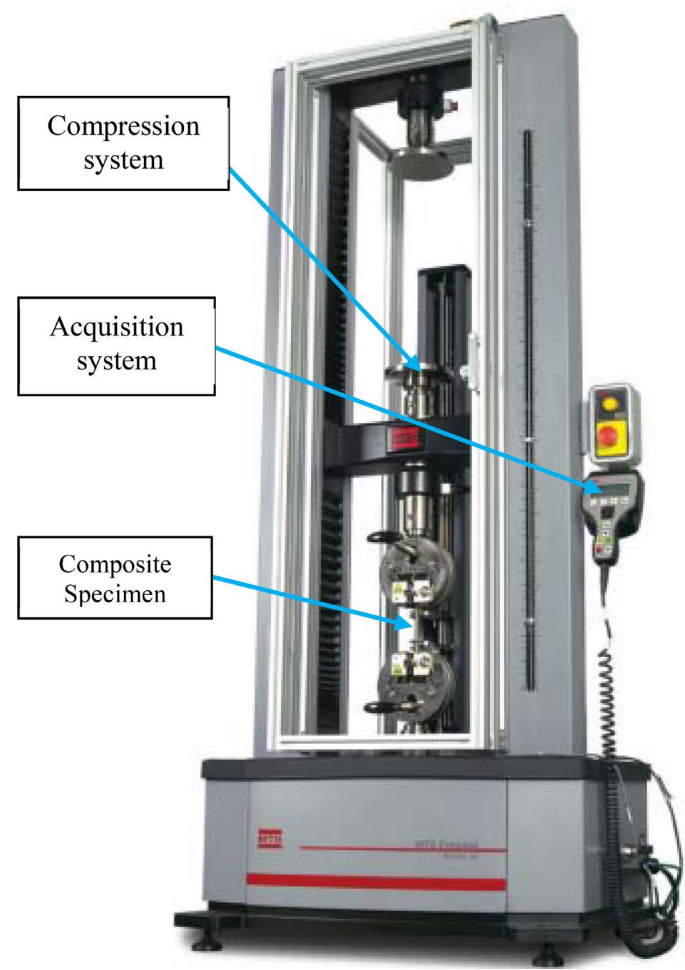

Figure 7. MTS criterion 40 series electromechanical universal test systems. 
materials with woven architecture. However, other research groups around the world have already performed characterization tests on woven materials using the standards defined for unidirectional fiber composite materials [26] [24].

Experimental tests objective is to measure the sensitivity of different parameters by selecting four trigger types; steeple, chamfer $45^{\circ}$, corrugated and saw teeth. Different stacking sequences; $[0 / 90]_{2 s},[0 / 45 / 45 / 0]_{s}$ and $[45 / 90 / 90 / 45]_{s}$ were also tested, and two crush velocities; $3 \mathrm{~mm} / \mathrm{min}$ and $4650 \mathrm{~mm} / \mathrm{s}$ were used.

Figure 8 shows the geometries of flat plate coupons with saw teeth, corrugated, steeple and chamfer $45^{\circ}$ triggers. In total, 24 samples were tested.

Flat plates are preferred for simple crush tests, because they are less sensitive to warping compared to other open section coupons with the presence of torsion by the eccentric forces, or in the presence of the instabilities in compression loads. In all cases, in the design of these sections, the phenomenon of warping is crucial.

\section{3) Boundary conditions}

A lateral support is added to prevent global buckling of specimens during crushing. The coupon is clamped between two aluminium 6560 metal blocks.

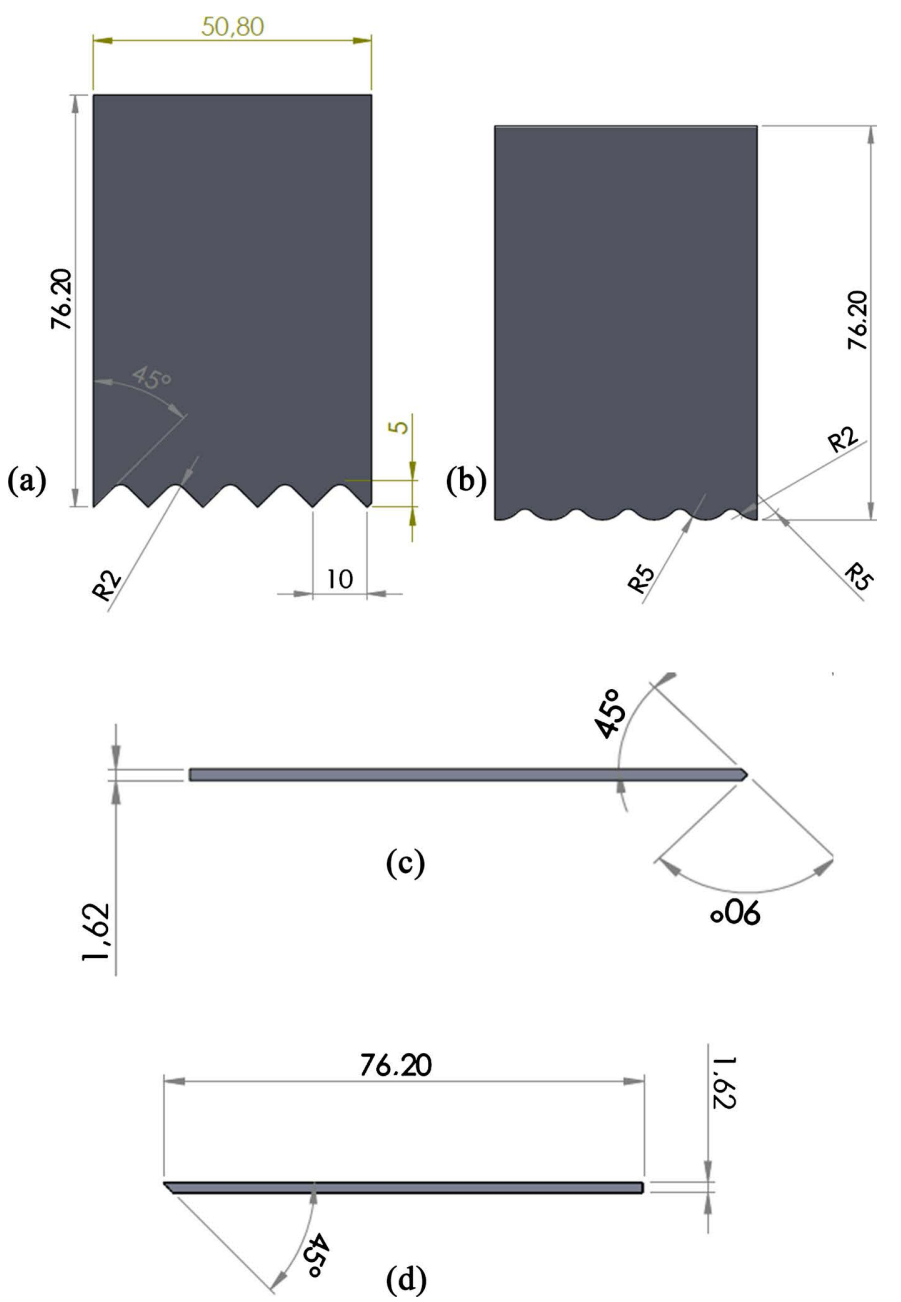

Figure 8. Flat plate coupons dimensions; (a): with saw teeth trigger; (b): with corrugated trigger; (c): with steeple trigger; (d): with Chamfer $45^{\circ}$ trigger. 
Boundary conditions consists of friction between aluminum blocks and the composite coupon and friction between the front steel plate and the composite coupon, damage can occur if excessive clamping forces are used and frictionless contact between Aluminum clamps and composite coupons is also eliminated to avoid possible lateral movement. The coefficients of friction can be evaluated with the ASTM standards.

A coefficient of friction of 0.15 is used for the contact between steel fixed plate and composite coupon in crush front. Between the aluminum clamps and coupon, a friction coefficient of 0.2 is chosen. The constant width of the coupons is $50.8 \mathrm{~mm}$ and the free unsupported height was chosen for $10 \mathrm{~mm}$ in order to avoid global buckling phenomenon. The cross-section surface of specimens is thus $82.5 \mathrm{~mm}^{2}$.

The free height of the specimens is a crucial parameter that was determined before the present work during the design stage of an optimised height for crush tests.

Figure 9 shows the boundary conditions adopted for the present experimental work. For QS conditions, tests were stopped manually after 4 to $8 \mathrm{~mm}$ of crashed material stroke distance. However, for Low Velocity crush conditions, tests were stopped automatically, because the amount of energy delivered by drop tower was limited to crush a maximum of $6 \mathrm{~mm}$ height of composite coupons. The progression of the crushing event was monitored using instrumentation facilities, such as GOM DIC Aramis, fast camera and extensometer. Some coupons were prepared for optical microscopic observations.

\section{Experimental Results}

\section{1) $1^{\text {st }}$ Tests campaign: Quasi static Crush Results:}

Quasi-static compression tests were carried out at $3 \mathrm{~mm} / \mathrm{min}$ of compression speed during 4 to $8 \mathrm{~mm}$ of stroke distance using a universal MTS Criterion Series 40 pressure test machine. Figure 10, Figure 11 \& Figure 12 show final crush fronts. Fragmentation increases for coupons with $[0 / 45 / 45 / 0]_{s}$ Layup, and

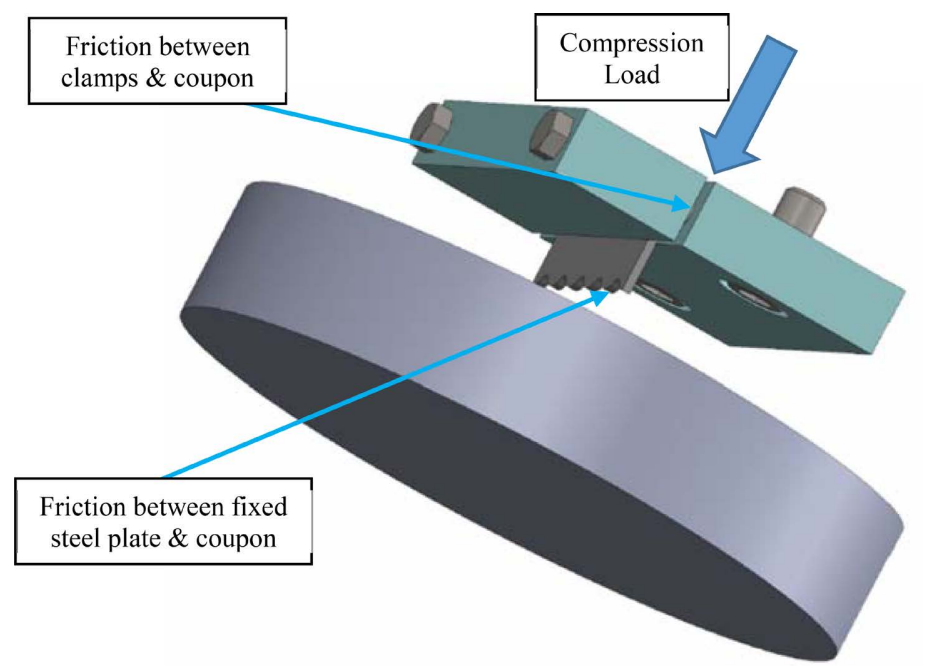

Figure 9. Flat plate coupon fixture boundary conditions. The illustration shows a coupon with corrugated trigger. 
delamination increases for coupons with $[45 / 90 / 90 / 45]_{\mathrm{s}}$ Layup.

$$
\text { For }[0 / 90]_{2 s} \text { Layup: }
$$

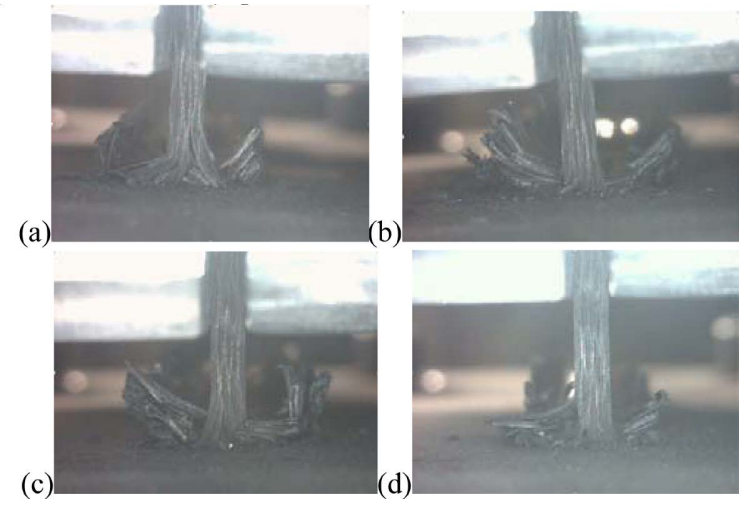

Figure 10. QS crush tests results for [0/90 $]_{2 \mathrm{~s}}$ Layup: (a) flat plate coupon with Chamfer $45^{\circ}$ trigger; (b) steeple trigger; (c) corrugated trigger; (d) saw teeth trigger.

\section{For $[0 / 45 / 45 / 0]_{s}$ Layup:}

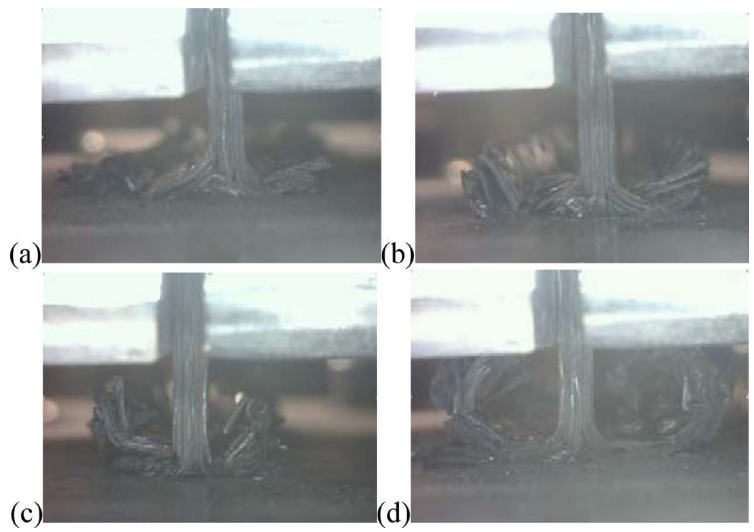

Figure 11. QS crush tests results for [0/45/45/0 $]_{s}$ Layup: (a) flat plate coupon with Chamfer $45^{\circ}$ trigger; (b) steeple trigger; (c) corrugated trigger; (d) saw teeth trigger.

\section{For $[45 / 90 / 90 / 45]_{s}$ Layup:}

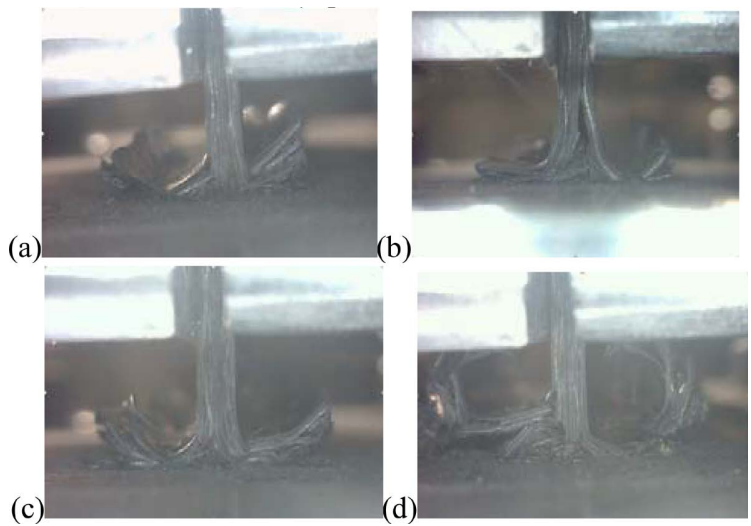

Figure 12. QS crush tests results for [45/90/90/45] Layup: (a) flat plate coupon with Chamfer $45^{\circ}$ trigger; (b) steeple trigger; (c) corrugated trigger; (d) saw teeth trigger. 
2) $2^{\text {nd }}$ Tests campaign: Low Velocity Crush Results.

Dynamic compression tests were performed at $4650 \mathrm{~mm} / \mathrm{s}$ of compression speed during $6 \mathrm{~mm}$ of stroke distance using drop tower Instron 9340 facility. Figure 13, Figure 14 \& Figure 15 show post-mortem coupons illustrating combined splaying and fragmentation crush mode. As above, fragmentation increases for coupons with $[0 / 45 / 45 / 0]_{s}$ layup, and delamination increases for coupons with $[45 / 90 / 90 / 45]_{s}$ layup.

For $[0 / 90]_{2 s}$ Layup:

(a)

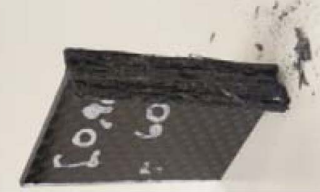

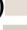

(c)

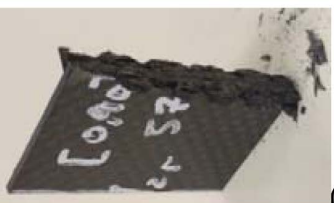

(b)

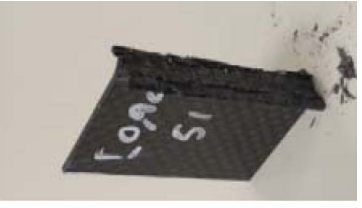

(d)

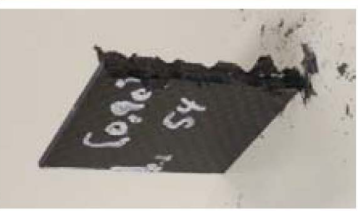

Figure 13. Dynamic crush tests results for $[0 / 90]_{2 s}$ Layup: (a) flat plate coupon with Chamfer $45^{\circ}$ trigger; (b) steeple trigger; (c) corrugated trigger; (d) saw teeth trigger.

\section{For $[0 / 45 / 45 / 0]_{s}$ Layup:}

(a)

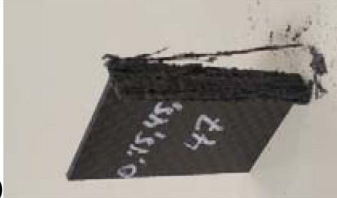

(c)

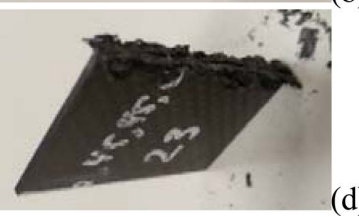

(b)

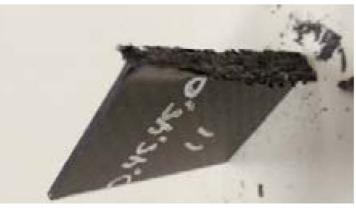

(d)

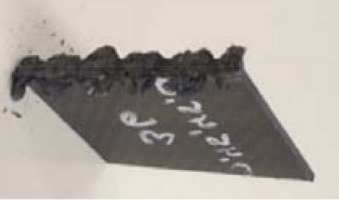

Figure 14. Dynamic crush tests results for $[0 / 45 / 45 / 0]_{s}$ Layup: (a) flat plate coupon with Chamfer $45^{\circ}$ trigger; (b) steeple trigger; (c) corrugated trigger; (d)saw teeth trigger.

\section{For $[45 / 90 / 90 / 45]_{s}$ Layup:}

(a)

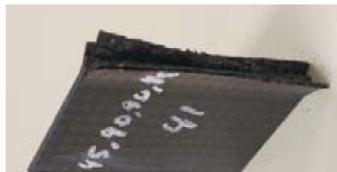

(c)

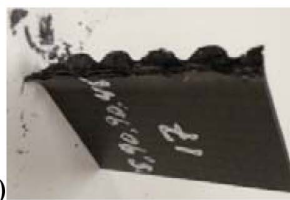

(b)

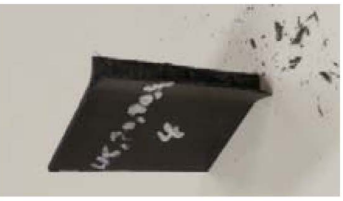

(d)

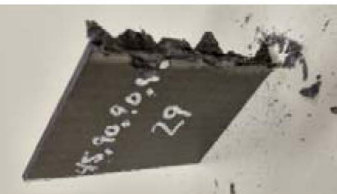

Figure 15. Dynamic crush tests results for [45/90/90/45] Layup: (a) flat plate coupon with Chamfer $45^{\circ}$ trigger; (b) steeple trigger; (c) corrugated trigger; (d)saw teeth trigger. 
The absorbed energy by the specimen during crushing is equal to the area beneath the load-displacement curve, and could be calculated by the equation:

$$
A_{e}=\int_{0}^{l} P(z) d z
$$

where $Z$ is the stroke, and $P$ is the applied load

The SEA is equal to the absorbed energy per unit of crushed specimen mass, and could be defined by the equation:

$$
S E A=\frac{A}{\rho A l}=\frac{\int_{0}^{l} P(z) d z}{\rho A l}
$$

where $\rho$ is the density, $A$ is the cross section area of specimen.

For the QS tests, the different applied load $P$ vs. the stroke $z$ curves are shown in the following; Figure 16 to Figure 19.

For the Dynamic tests, applied load vs. stroke curves are shown in Figure 20 to Figure 23.

\section{Numerical Modeling}

In order to verify a pre-developed numerical tool UL-Crush, [27], an explicit 3D crush analysis of flat plate coupon was carried out within Abaqus2020. The numerical model is shown in Figure 24 with finer mesh. Some simplifications were
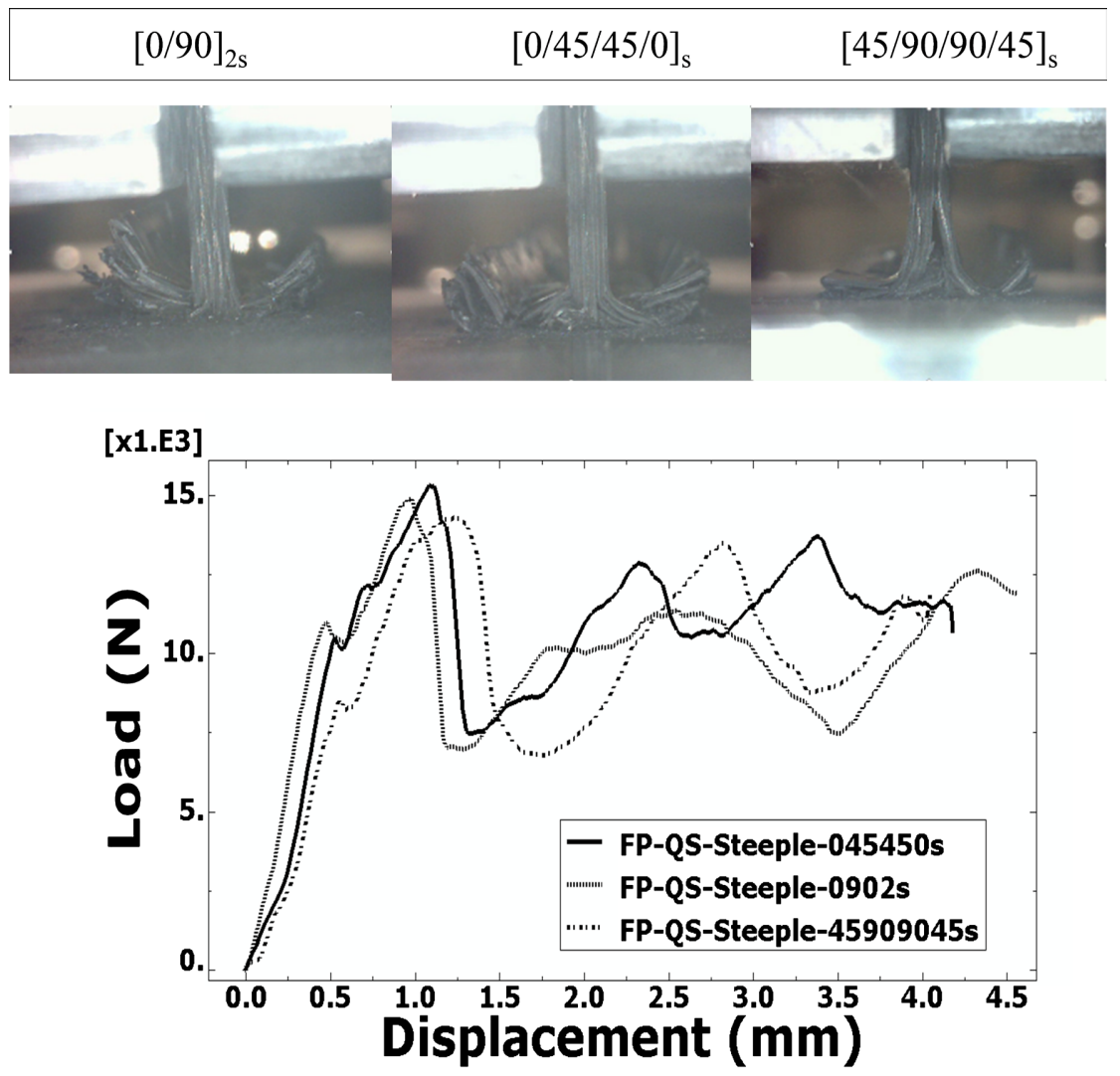

Figure 16. Load P vs. the stroke $\mathrm{z}$ for QS crush tests of steeple trigger coupons. 

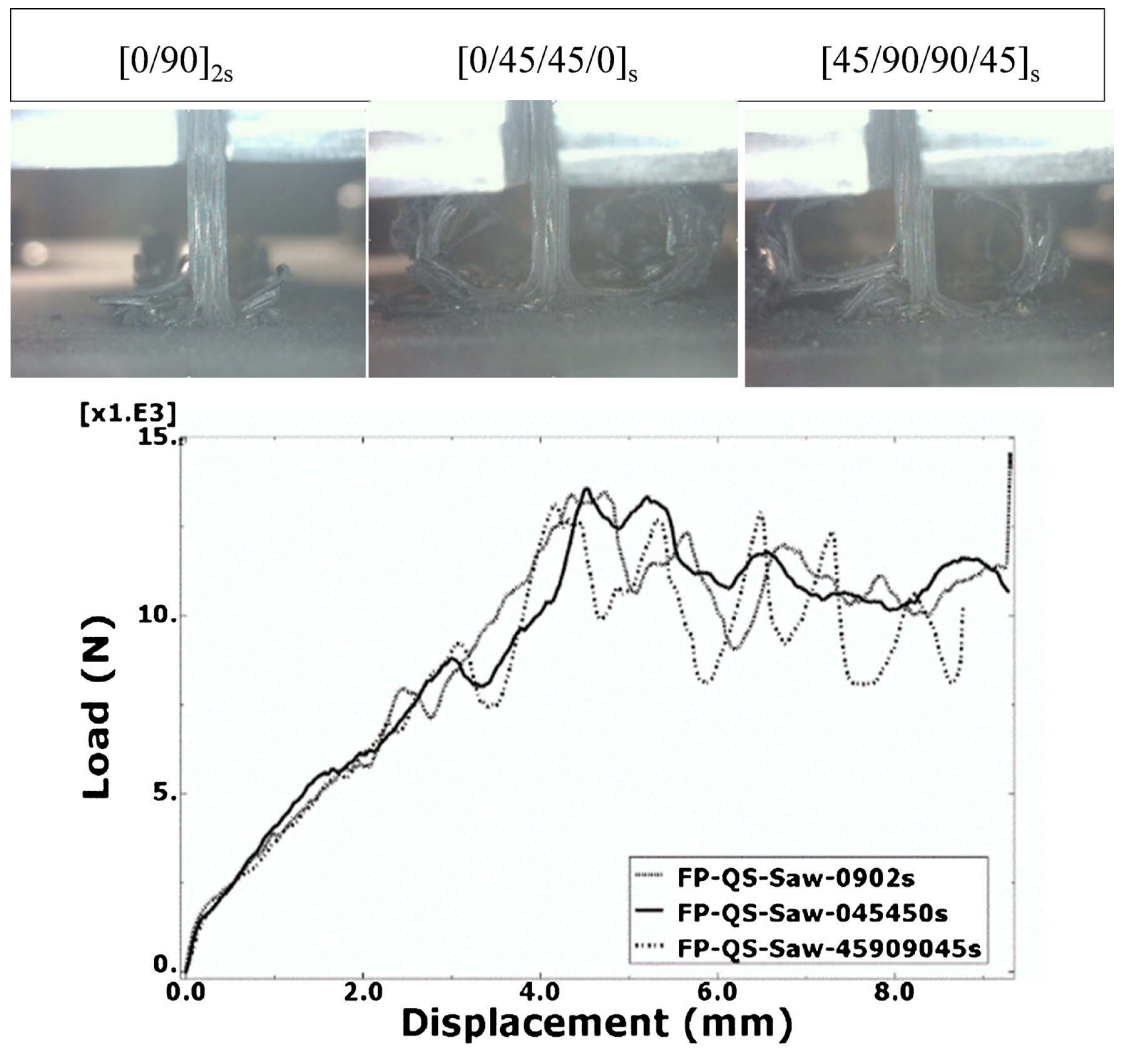

Figure 17. Load P vs. the stroke $\mathrm{z}$ for QS crush tests of saw teeth trigger coupons.
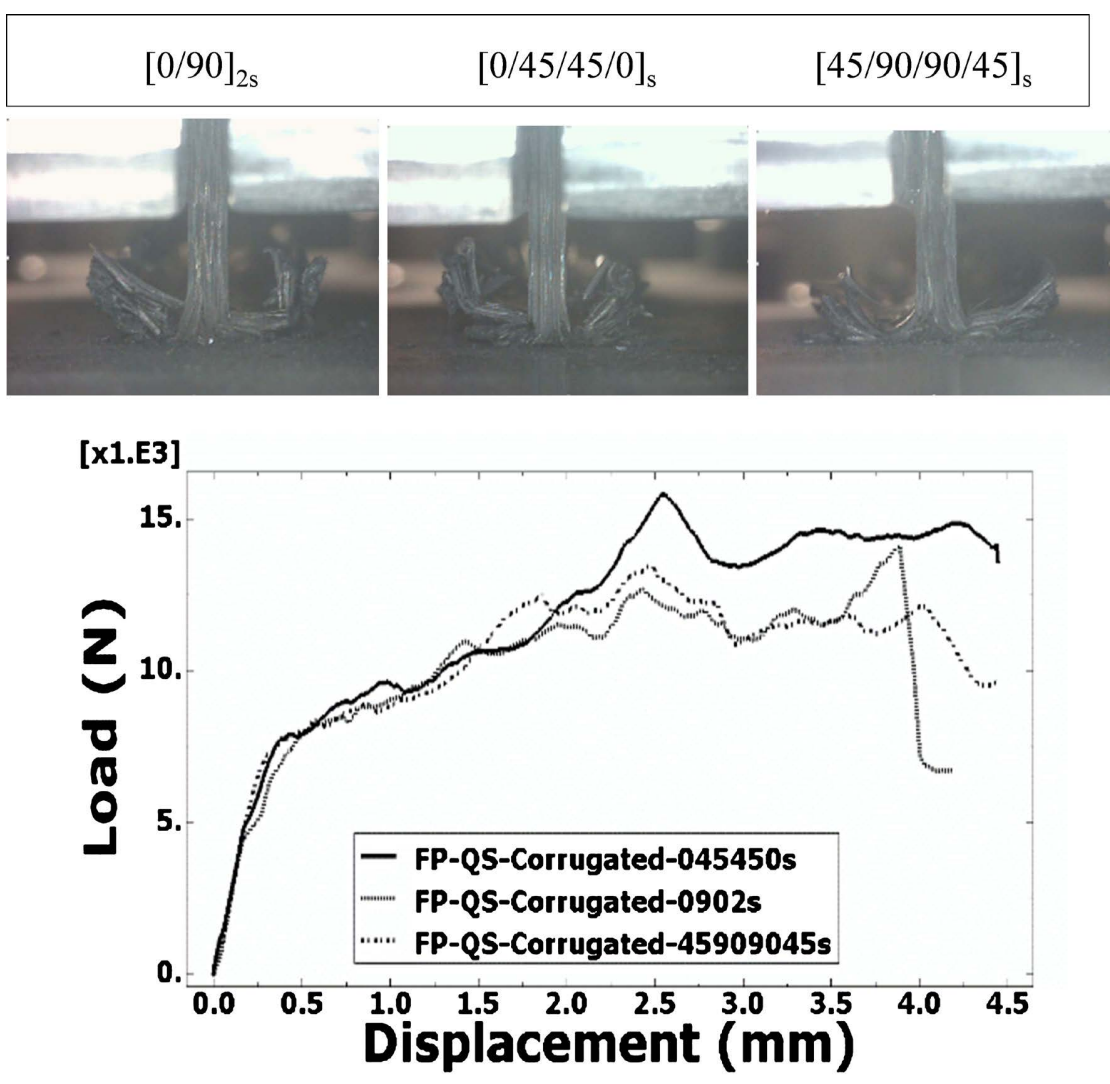

Figure 18. Load P vs. the stroke $\mathrm{z}$ for QS crush tests of corrugated trigger coupons. 


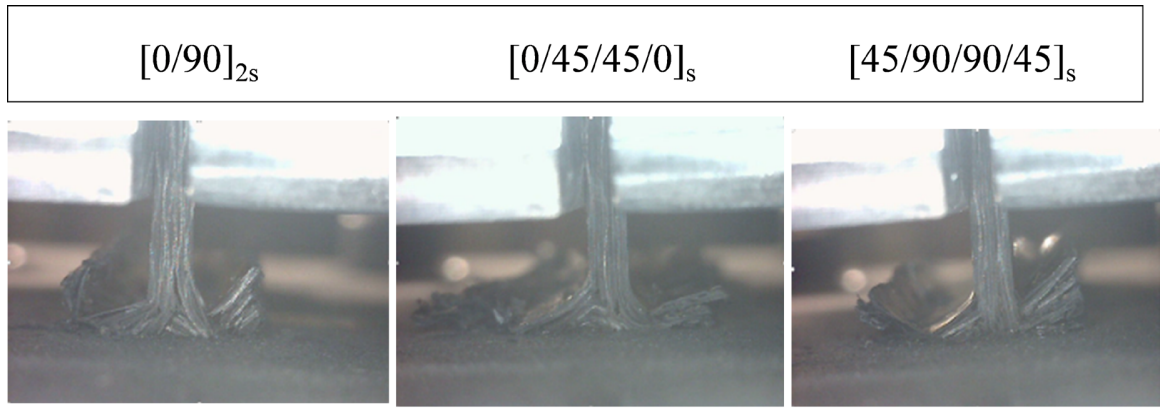

[x1.E3]

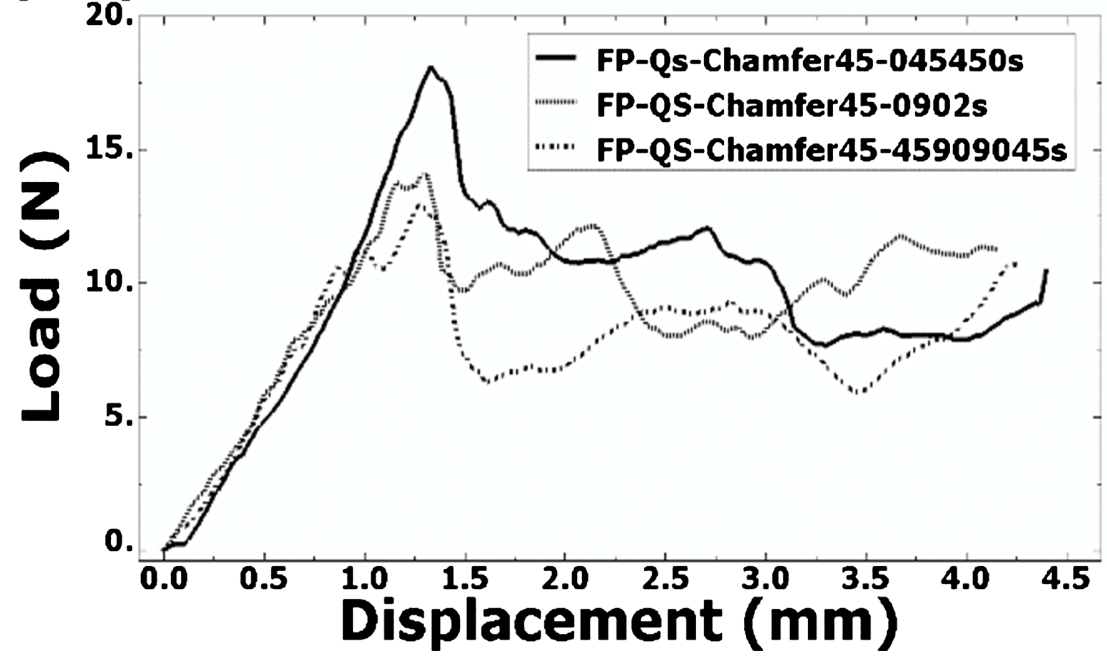

Figure 19. Load $\mathrm{P}$ vs. the stroke $\mathrm{z}$ for QS crush tests of chamfer $45^{\circ}$ trigger coupons.
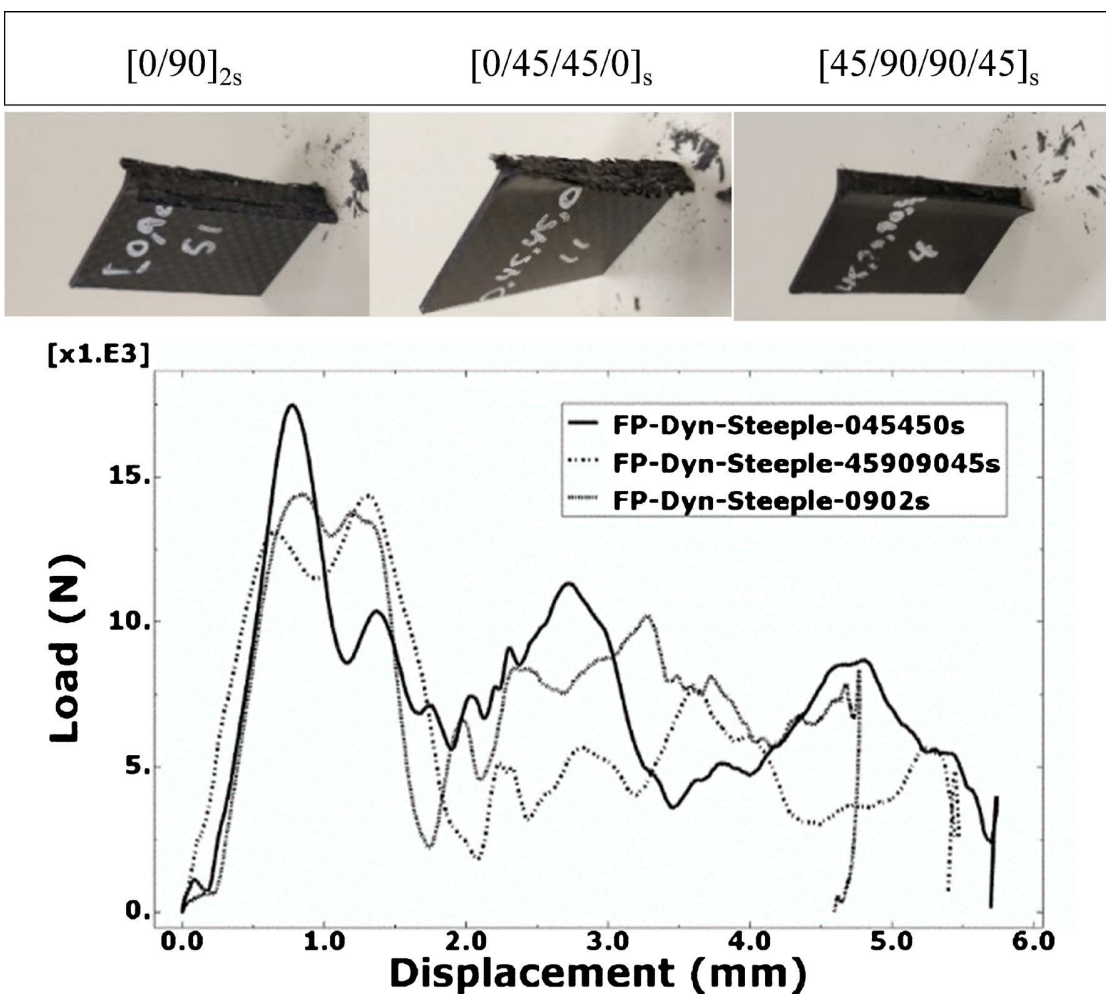

Figure 20. Load P vs. the stroke $\mathrm{z}$ for Dyn crush tests of steeple trigger coupons. 

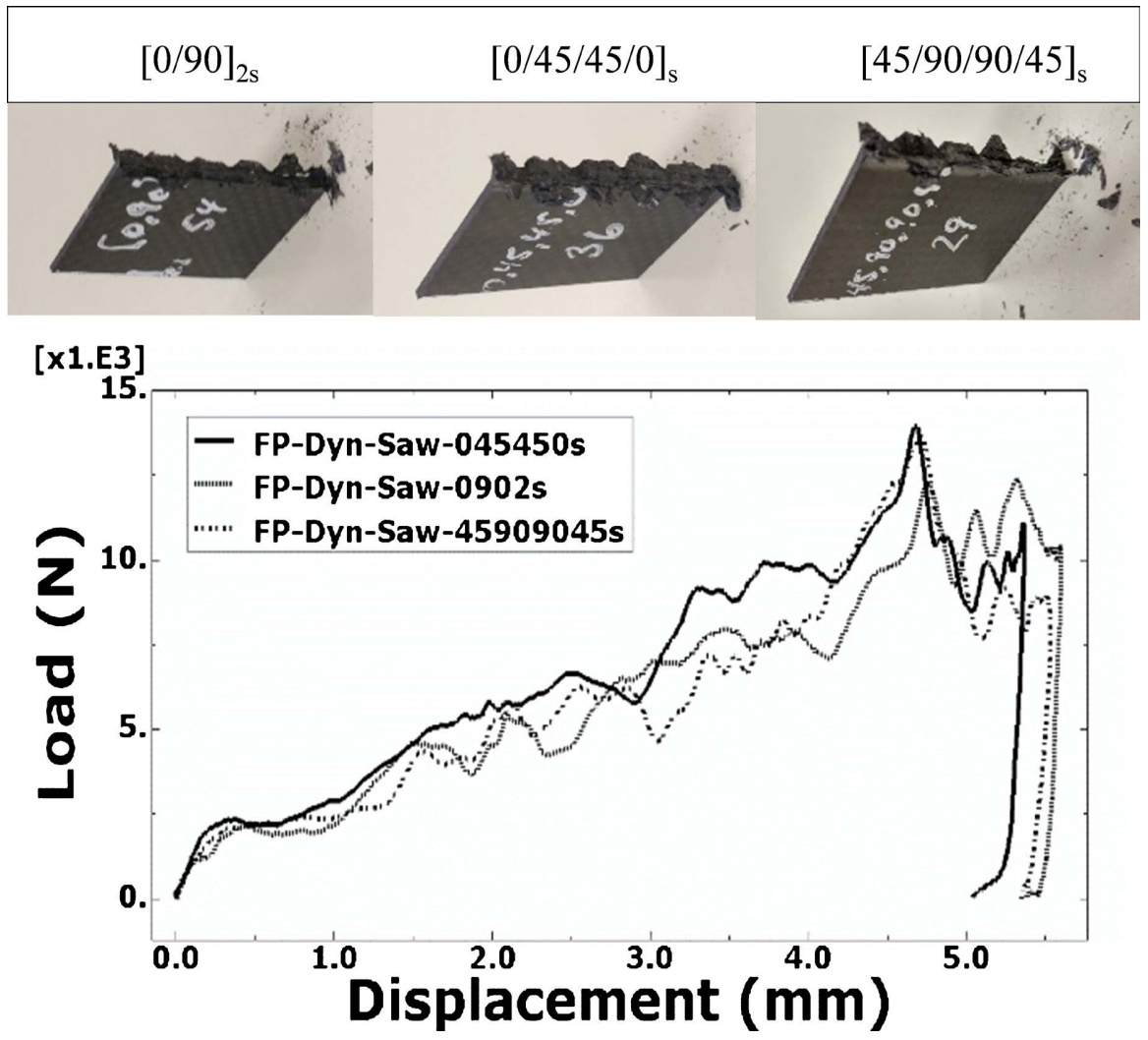

Figure 21. Load P vs. the stroke $\mathrm{z}$ for Dyn crush tests of saw-teeth trigger coupons.
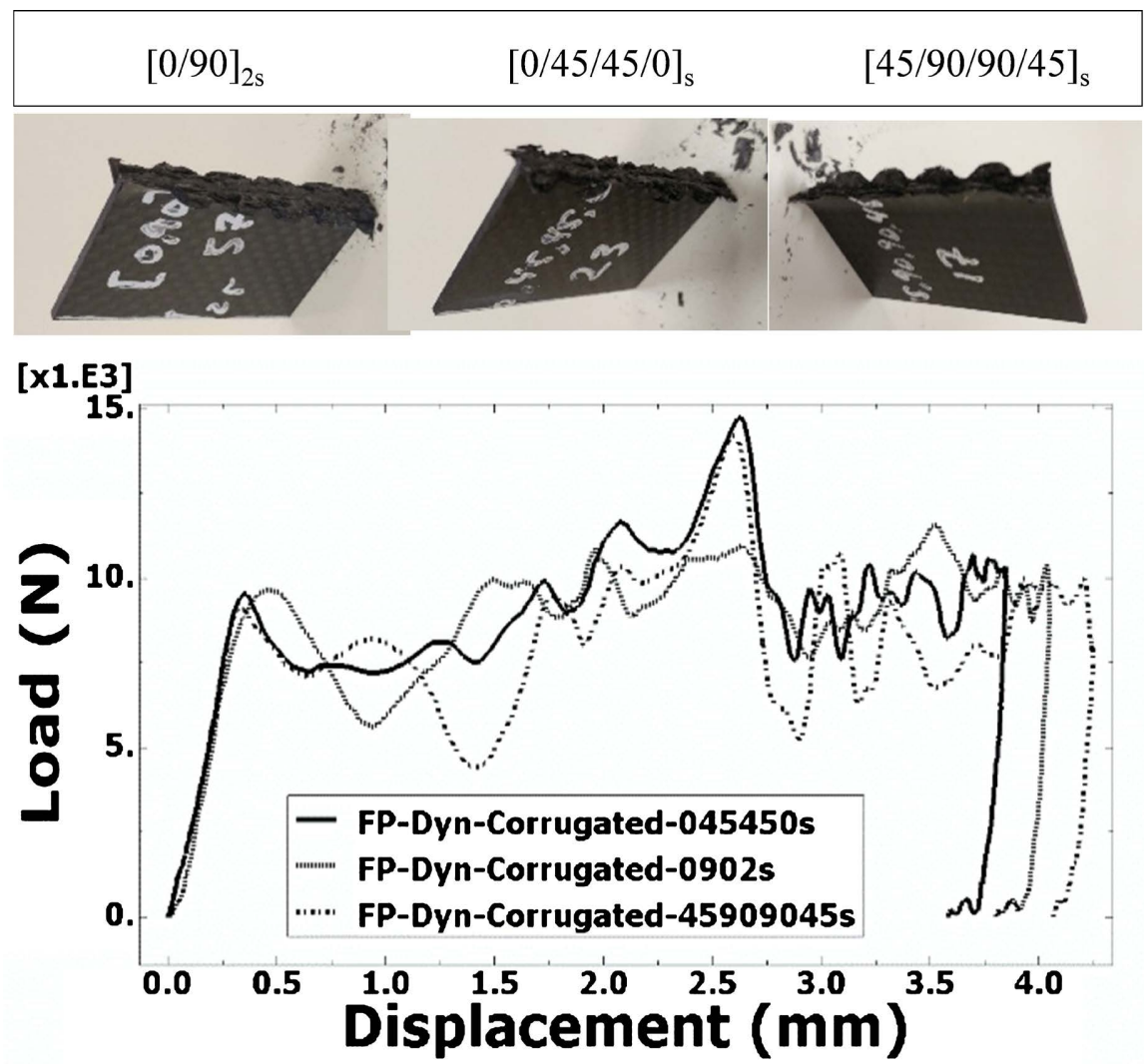

Figure 22. Load P vs. the stroke $\mathrm{z}$ for Dyn crush tests: corrugated trigger coupons. 


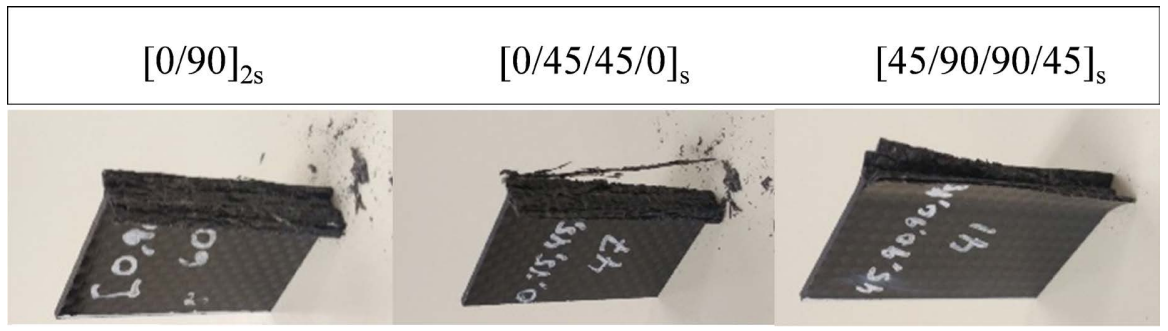

[X1.E3]

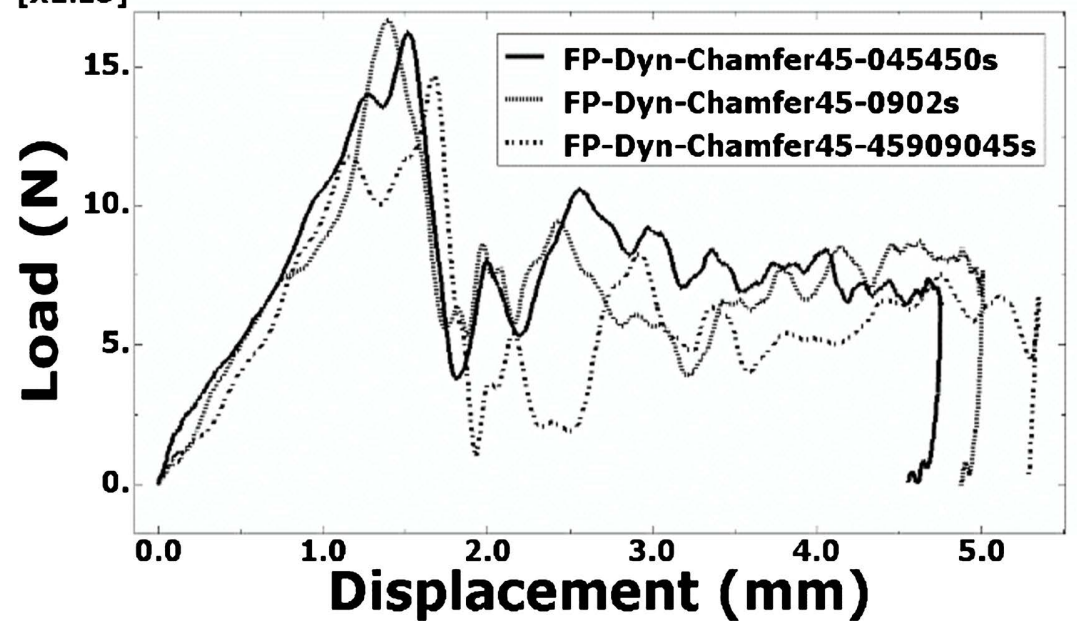

Figure 23. Load P vs. stroke $\mathrm{z}$ for Dyn crush tests: Chamfer $45^{\circ}$ trigger coupons.

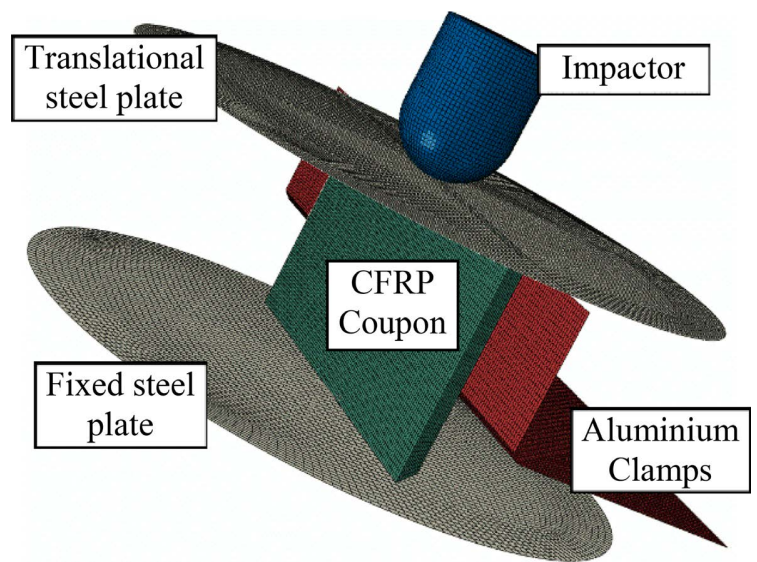

Figure 24. Simplified experimental fixture modeled within Abaqus simulation environment.

adopted to reduce the computational time. Steel solid fixed and translational plates are simplified to Steel shells, Aluminum solid clamps are also simplified to Aluminum shells. Fixed analytically rigid bodies are placed on the bottom, and largest vertical sides of the coupon. The friction coefficient between the coupon and the steel rigid bottom body is 0.15 , and between the coupon and the aluminum clamps is 0.2 .

The loading was introduced by applying to the top steel plate, a vertical constant velocity of $3 \mathrm{~mm} / \mathrm{min}$ for QS and vertical initial velocity of $4650 \mathrm{~mm} / \mathrm{s}$ for dynamic tests. 
This modeling approach considers one layer of solid elements per one real ply of laminate. Solid elements with reduced integration (C3D8R) were used to mesh the intra composite plies. To model the behavior of interface between plies, COH3D8 cohesive elements were used.

Abaqus/Explicit offers Hourglass and distortion control to prevent solid elements from inverting or distorting excessively for these cases. If distortion control is used, the energy dissipated by distortion control can be output upon request, [28]. UL-Crush constitutive material model was affected to the C3D8R elements.

The constitutive model of a material system is the relation between physical properties to describe behavior of the system under loading and boundary conditions.

UL-Crush 3D constitutive model, [27], implemented as user subroutine VUMAT, used for modeling plies has been developed to predict behavior of plain weave fabric woven CFRP composites, which is an improvement of Abq_ply_Fabric 2D material model embedded within the commercial code Abaqus/Explicit [28].

Abq_ply_Fabric has the potential to sustain a progressive stiffness degradation and provides a homogeneous orthotropic linear elastic formulation with damage initiation and evolution laws. Such laws based on fracture energies ensure that the correct amount of energy dissipates [29] [30] [31] [32].

UL-Crush 3D material model enhances 2D Abq_Ply_Fabric model by adding a modified Hashin 3D failure criteria, kin-banding modeling, fragmentation formulation and strain rate sensitivity modeling [27].

The simulations were performed using node in Calcul-Québec Cedar supercomputer with Abaqus/Explicit and domain parallelization.

\section{Discussion}

After analysing different experimental results and the loads vs. stroke curves, it was observed that the crush mode observed is a hybrid splaying-fragmentation mode. The coupons with $[0 / 45 / 45 / 0]_{s}$ layup achieves a high amount of compressive fragmentation failure due to 0 degree internal plies ability to fragment under the crush load. For dynamic crushing, the coupons seem to present internal disintegration involving less absorbed energy compared to quasi static crushing [22]. The type of triggers has a strong influence on the compressive response; the new proposed corrugated trigger improves the specimen stability during the crushing tests.

It has been also observed that the corrugated teeth trigger increases the amount of dissipated energy of the coupons, especially in QS case, due to the multiplication of damage mechanisms during the first period of crushing the height of the trigger.

The different amounts of SEA are presented in Table 1. The largest calculated SEA is highlighted in the table and is equal to $0.1289 \mathrm{Joule} / \mathrm{mm}^{3}$. It is related to the coupon with $[0,45,45,0] s$ layup, corrugated trigger and QS test case. 
Figure 25 illustrates the classification of different crush tests. SEA for QS tests are clearly higher than SEA for low velocity tests. Coupons are classified regarding SEA amounts calculated respectively from higher to lower; with $[0 / 45 / 45 / 0]_{s}$, $[0 / 90]_{2 s}$ and $[45 / 90 / 90 / 45]_{s}$ layups, and with corrugated, steeple, chamfer $45^{\circ}$ and saw teeth triggers.

The Delamination was one of the major damage mechanisms observed during

Table 1. Comparison between measured SEA amounts for crush tests.

\begin{tabular}{cccc}
\hline Layups & Triggers & SEA (Dyn) Joule $/ \mathrm{mm}^{3}$ & SEA (QS) Joule $/ \mathrm{mm}^{3}$ \\
\hline steeple & 0.0787 & 0.1181 \\
\hline $45,90,90,45]_{\mathrm{s}}$ & saw & 0.0769 & 0.1065 \\
& Corrugated & 0.0990 & 0.1213 \\
& Chamfer $45^{\circ}$ & 0.0741 & 0.0996 \\
\hline$[0,45,45,0]_{s}$ & steeple & 0.0903 & 0.1148 \\
& saw & 0.0877 & 0.1209 \\
& corrugated & 0.1190 & 0.1289 \\
& Chamfer $45^{\circ}$ & 0.0903 & 0.1212 \\
\hline 0,90$]_{2 \mathrm{~s}}$ & steeple & 0.0993 & 0.1183 \\
& saw & 0.0787 & 0.1094 \\
& corrugated & 0.1130 & 0.1210 \\
& Chamfer $45^{\circ}$ & 0.0921 & 0.1120
\end{tabular}

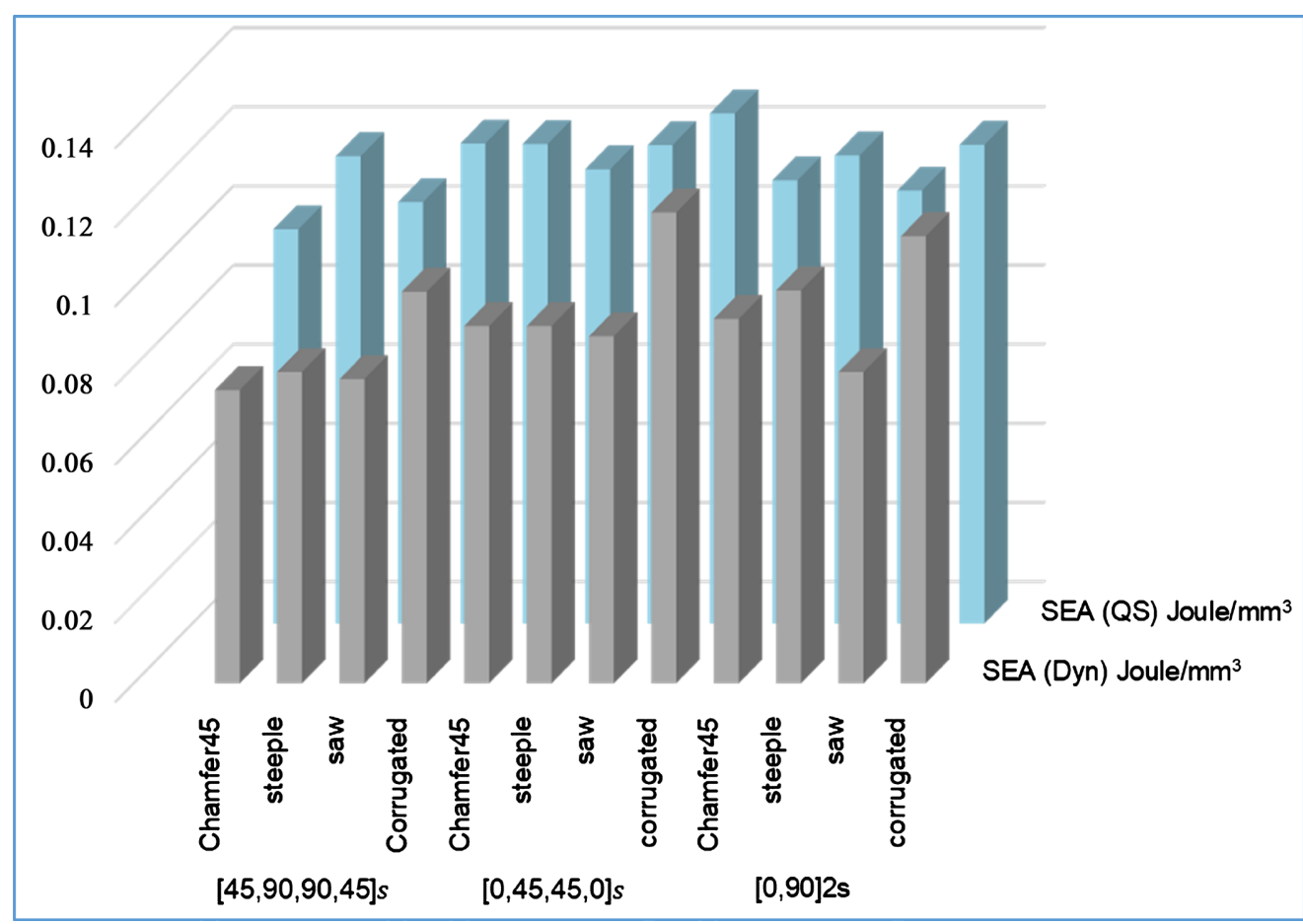

Figure 25. Chart comparison for specific energy absorption of crush tests. 
crush of flat plate coupons. All types of triggers produce a local stress concentration, resulting into the initiation of delamination or splaying failure mode. In real crush event, Mode I, Mode II and Mode III fracture are usually coupled and combined with a complex delamination mode.

The first effect of crush was characterized by a peak force, followed by a load drop, associated with a delamination damage mechanism. The second effect of crush was a steady state crushing load period. The ratio between sustainable load and peak force was slightly less then one, for coupons with saw teeth and corrugated trigger, and between 0.5 and 0.8 for coupons with chamfer $45^{\circ}$ and steeple trigger.

Figure 26 shows different steps of crushing and corresponding positions in Load vs Displacement curve. The first drop in the curve (from position 2 to 3 ) is the result of delamination and of the decrease of total supporting surface in the crush front.

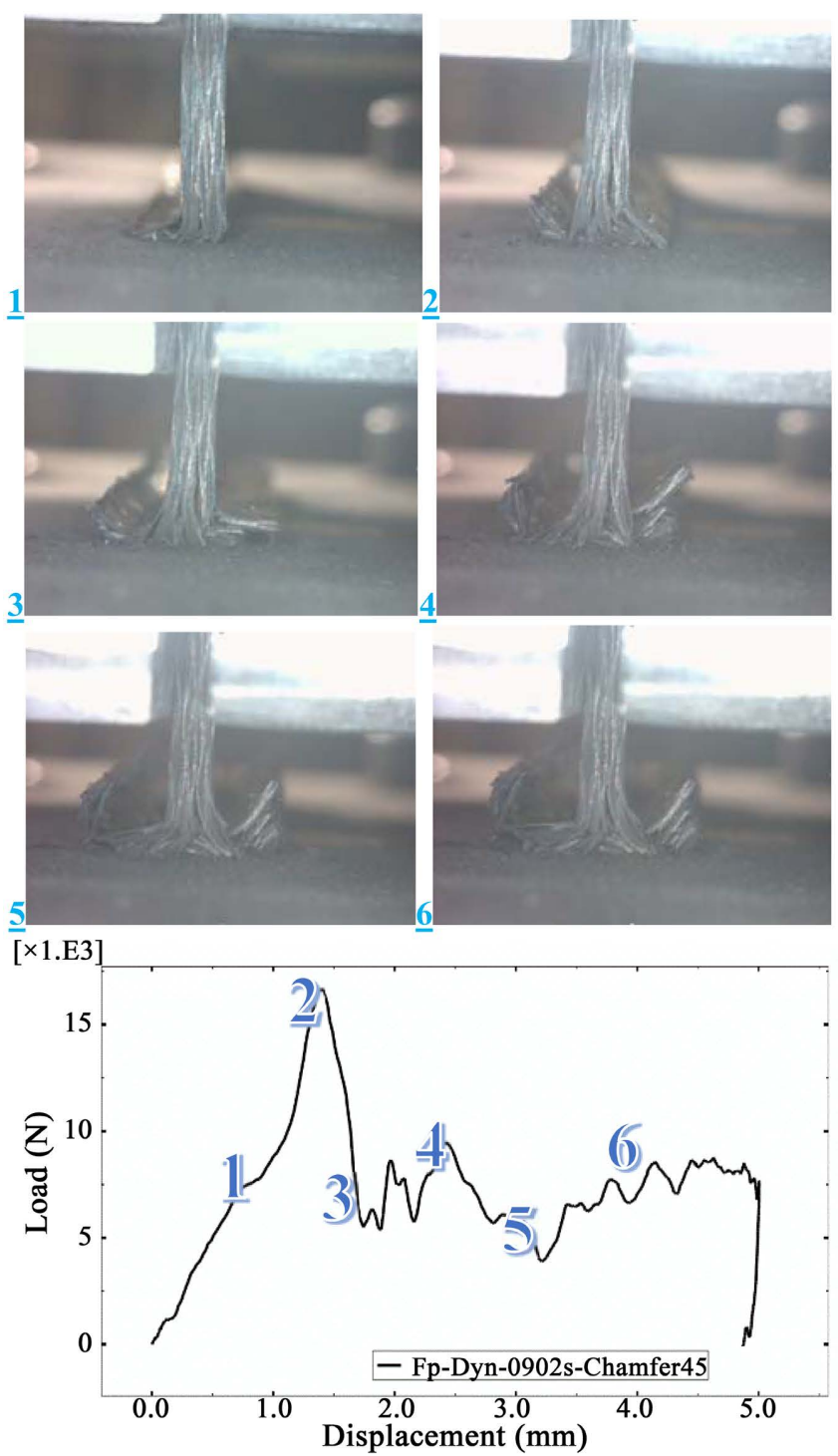

Figure 26. Crush scenario and Load P vs. stroke $\mathrm{z}$ for crush test of coupon with Chamfer $45^{\circ}$ trigger and $[0 / 90]_{2 s}$ layup. 
External fronds or petals resulting from delamination fails but remain attached to the central body of the coupon due to the braided architecture of plain weave fabric.

Internal plies produce fragments in the crush front and the accumulation of debris between delaminated plies and steel rigid wall stiffens the coupons and contributes to the sustainability of high level of post peak stable crush load involving to supplemental energy absorption. In addition, internal fragments push external plies to delaminate and reproduce the same cycle of crush scenario.

A delay was observed between the load vs. stroke curves. First for coupons with $45^{\circ}$ chamfer trigger and steeple trigger and then for coupons with saw teeth trigger and corrugated trigger, the long period to reach the steady state crushing load can be partially attributed to the difference of time for steel wall to be in contact with the entire cross section of the flat plate coupon and the difference of trigger heights. The height of chamfer $45^{\circ}$ and steeple trigger is $1.624 \mathrm{~mm}$ compared to $5 \mathrm{~mm}$ for saw teeth and corrugated trigger.

Figure 27 shows a comparison between Experimental, Abq_Ply_Fabric and UL-Crush dynamic results for flat coupon with $[0 / 90]_{2 \mathrm{~s}}$ layup and chamfer $45^{\circ}$ trigger type, with the new fixture designed for this study.

The numerical curves of Abq_Ply_Fabric and UL-Crush has a SAE600 filtering operator with $600 \mathrm{~Hz}$ filter applied to smooth out the numerical prediction.

Abq_Ply_Fabric seems to capture peak force but sur-estimate the sustainable post peak crush load. However, UL-Crush capture well the post peak crush load and under-estimate peak force.

Figure 28 shows a comparison of damages occurred after crush test between the experimental and the UL-Crush 3D material model simulation results for flat coupon with $[0 / 90]_{2 s}$ layup and chamfer $45^{\circ}$ trigger type.

\section{Conclusions}

In order to evaluate and compare crushing behavior of aerospace grade composite

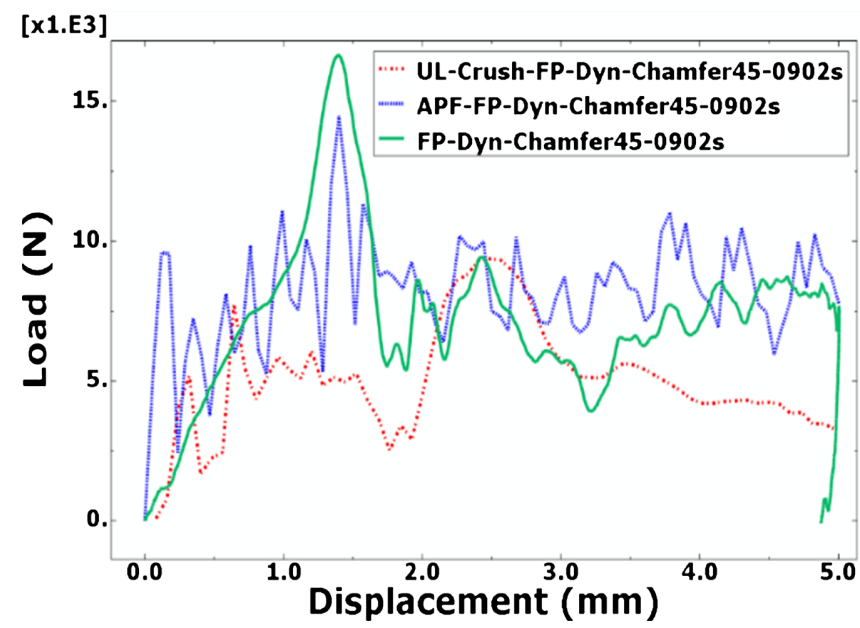

Figure 27. Comparison between experimental, Abq_Ply_Fab and UL-Crush dynamic results for flat coupon with $[0 / 90]_{2 s}$ layup and chamfer $45^{\circ}$ trigger type 


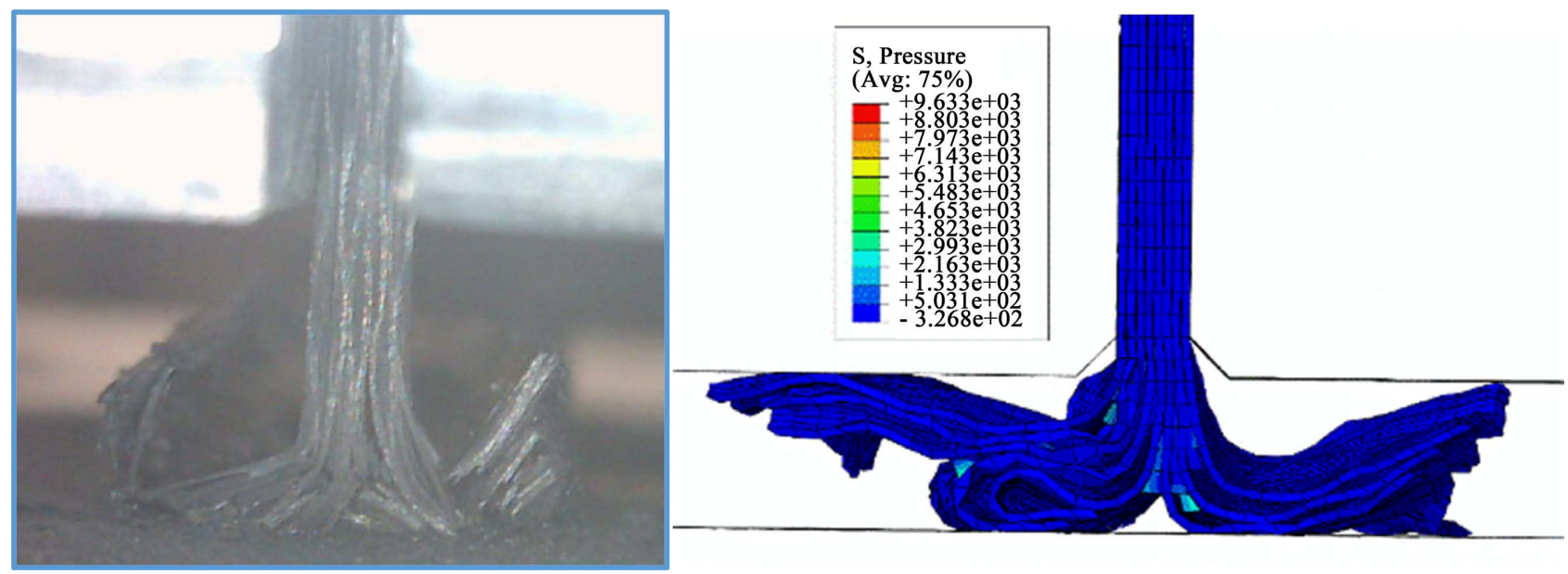

Figure 28. Comparison between experimental and UL-Crush results for flat coupon with $[0 / 90]_{2 s}$ layup and chamfer $45^{\circ}$ trigger type.

material, a new experimental approach was implemented with coupon level testing for a cost-effective method to study in depth the crashworthiness capabilities of aerospace graded composite structures.

Flat plate coupons were adopted to analyse failure mechanisms and instead of complicated dedicated anti-buckling fixture, a simplified fixture with aluminum clamps was used with controlled free unsupported height to avoid global buckling and catastrophic crush.

The sensitivity of different parameters is investigated with the aim of choosing the best material configuration absorbing a high amount of energy for aerospace applications to mitigate shocks and impacts.

Regarding the influence of triggers, it has been shown that the traditional chamfer $45^{\circ}$, saw teeth or steeple triggers dissipate less energy by leading to out-of-plane failure by delamination with a limited amount of in-plane fracture by fragmentation, while the proposed corrugated triggers achieve a higher amount of energy by higher in plane failure by fragmentation.

Regarding the sensitivity of layups; Coupons with [0/45/45/0] layup, with internal 0 degree oriented plies, dissipates more energy by fragmentation, due to the ability of this type of oriented plies to fragmentation. Coupons with $[0 / 90]_{2 \mathrm{~s}}$ and $[45 / 90 / 90 / 45]_{s}$ layups achieve less amount of energy compared to $[0 / 45 / 45 / 0]_{s}$ oriented coupons.

Regarding the effect of strain rates on the absorbed energy, it has been shown that coupons absorb more energy in QS crush tests compared to low velocity crush tests.

The calculated SEA of the best material configuration in terms of dissipating energy, is about $0.1289 \mathrm{Joule} / \mathrm{mm}^{3}$, for flat plate coupon with corrugated trigger, [0/45/45/0 $]_{s}$ layup and tested in QS crush load condition.

To validate a pre-developed material model UL-Crush, [27], an example of numerical simulation was performed for comparison between UL-Crush, Abq Ply_Fabric embedded material model within Abaqus/Explicit commercial code 
and experimental results.

Numerical results show that the physics behind crushing is well captured and predicted.

In general, all relevant effects of crush were sufficiently predicted by the model; nonetheless, the peak crush load was slightly under-predicted compared to the experimental results.

The comparison between simulation and experimental results highlighted the capabilities of the UL-Crush material model to predict the crush behavior of flat plate coupons with good accuracy.

A new hybrid FEM/SPH material model is in development for improving the fragmentation prediction capacity of the UL-Crush numerical tool.

\section{Acknowledgements}

The authors declared no potential conflicts of interest with respect to the research, authorship, and/or publication of this article.

The authors would like to thank the Natural Science and Engineering Research Counsel of Canada (NSERC), Consortium for research and innovation in aerospace in Quebec (CRIAQ) through CRIAQ Project COMP-410, Bombardier Aerospace and Bell Helicopter Textron Company (BHTC) for funding, technical support and materials.

\section{Conflicts of Interest}

The authors declare no conflicts of interest regarding the publication of this paper.

\section{References}

[1] Wade, B. (2014) Capturing the Energy Absorbing Mechanisms of Composite Structures under Crash Loading. University of Washington, Washington DC.

[2] Guida, M., Marulo, F. and Abrate, S. (2018) Advances in Crash Dynamics for Aircraft Safety. Progress in Aerospace Sciences, 98, 106-123. https://doi.org/10.1016/j.paerosci.2018.03.008

[3] Ala, T. and Sandeep, M. (2018) A Non-Linear Strain-Rate Micro-Mechanical Composite Material Model for Impact Problems. 15th International LS-DYNA Users Conference, Detroit, 10-12 June 2018, 1-22.

[4] Fasanella, E.L. and Jackson, K.E. (2002) Best Practices for Crash Modeling and Simulation. NASA/TM-2002-211944, ARL-TR-2849. National Aeronautics and Space Administration, Army Research Lab, Vehicle Technology Directorate, Hampton, VA.

[5] Sause, M.G.R. (2016) In Situ Monitoring of Fiber-Reinforced Composites: Theory, Basic Concepts, Methods, and Applications. Vol. 242, Springer International Publishing, Cham. https://doi.org/10.1007/978-3-319-30954-5

[6] Garcea, S., Wang, Y. and Withers, P. (2018) X-Ray Computed Tomography of Polymer Composites. Composites Science and Technology, 156, 305-319. https://doi.org/10.1016/j.compscitech.2017.10.023

[7] Zhuang, F., Chen, P., Arteiro, A. and Camanho, P. (2019) Mesoscale Modeling of 
Damage in Half-Hole Pin Bearing Composite Laminate Specimens. Composite Structures, 214, 191-213. https://doi.org/10.1016/j.compstruct.2019.01.062

[8] McGregor, C.J. (2005) Simulation of Progressive Damage Development in Braided Composite Tubes under Axial Compression. Master's Thesis, University of British Columbia, Vancouver.

[9] Costa, S., Portugal, A., Olsson, R., Vyas, G. and Bru, T. (2017) Validation of a Novel Nodel for the Compressive Reponse of FRP: Numerical Simulation. 21 st International Conference on Composite Materials, Xi'an, 20-25 August 2017, 20-25.

[10] Hull, D. (1991) A Unified Approach to Progressive Crushing of Fibre-Reinforced Composite Tubes. Composites Science and Technology, 40, 377-421.

https://doi.org/10.1016/0266-3538(91)90031-J

[11] Czaplicki, M., Robertson, R. and Thornton, P. (1991) Comparison of Bevel and Tulip Triggered Pultruded Tubes for Energy Absorption. Composites Science and Technology, 40, 31-46. https://doi.org/10.1016/0266-3538(91)90041-M

[12] Jimenez, M., Miravete, A. and Larrode, E. (2000) Effect of Trigger Geometry on Energy Absorption in Composite Profiles. Composite Structures, 48, 107-111. https://doi.org/10.1016/S0263-8223(99)00081-1

[13] Falzon, B. and Wand, T. (2016) Modelling the Crush Behaviour of the Thermoplastic Composites. Composites Science and Technology, 134, 57-71. https://doi.org/10.1016/j.compscitech.2016.07.015

[14] Lombarkia, R., Gakwaya, A., Nandlall, D., Dano, M.-L., Lévesque, J. and VachonJoannette, P. (2020) Experimental Investigation and Finite-Element Modeling of the Crushing Response of Hat Shape Open Section Composites. International Journal of Crashworthiness, Published Online 29/10/2020. https://doi.org/10.1080/13588265.2020.1838773

[15] CMH-17 (2017) Chapter 16. Crashworthiness and Energy Management. Composite Materials Handbook: Polymer Matrix Composites-Materials Usage, Design, and Analysis (CMH-17), Vol. 3, SAE International, Warrendale.

[16] Nailadi, C. (2005) A Summary of the ACC Tube Testing Program. Proceedings of the 49 th MIL-HDBK-17 Coordination Meeting, Santa Monica, CA, December 2005.

[17] Lavoie, J. and Morton, J. (1993) Design and Application of a Quasi-Static Crush Test Fixture for Investigating Scale Effects in Energy Absorbing Composite Plates. NASA Contractor Report-4526, National Aeronautics and Space Administration, Virginia Polytechnic Institute and State University, Blacksburg, Virginia.

[18] Johnson, A. and Kohlgruber, D. (2000) Design and Performance of Energy Absorbing Subfloor Structures in Aerospace Applications. iMechE Seminar S672: Materials and Structures for Energy Absorption, London, London, 9 May 2000.

[19] Wiggenraad, J. (2003) Crashworthiness Research at NLR: 1990-2003. NLR TP-2003-217. National Aerospace Laboratory NLR, Amsterdam.

[20] Guillon, D. (2009) Experimental and Numerical Study of the Splaying Mode Crush of CFRP Laminates. 17 th International Conference on Composite Materials, 27-31 July 2009, Edinburgh.

[21] Thomas, B., Paul, W., Renaud, G., Robin, O. and Gaurav, V. (2017) Development of a Test Method for Evaluating the Crushing Behaviour of Unidirectional Laminates. Journal of Composite Materials, 51, 4041-4051. https://doi.org/10.1177\%2F0021998317697811

[22] Salvi, A.G., Waas, A.M. and Caliskan, A. (2004) Rate-Dependant Compressive Behavior of Unidirectional Carbon Fiber Composites. Polymer Composites, 25, 397-406. 
https://doi.org/10.1002/pc.20033

[23] Chen, W. and Song, B. (2010) Split Hopkinson (Kolsky) Bar: Design, Testing and Applications. Springer, Boston. https://doi.org/10.1007/978-1-4419-7982-7

[24] Harizi, W., Monnin, A., Aboura, Z. and Benzeggagh, M. (2015) A New Hydraulic Crash Machine for Composite Structures. Journal of Dynamic Behavior of Materials, 1, 94-100. https://doi.org/10.1007/s40870-015-0004-8

[25] Meyers, M. (1994) Dynamic Behavior of Materials. Wiley, New York. https://doi.org/10.1002/9780470172278

[26] Benjamin, B. (2016) Étude de la délamination sur des matériaux composites tissés taffetas: Essais de caractérisation et simulations numériques. Université Laval, Québec.

[27] Lombarkia, R., Gakwaya, A., Nandlall, D., Dano, M.-L., Lévesque, J., Benkhelifa, A., Vachon-Joannette, P. and Gagnon, P. (2021) A Meso-Mechanical Material Model Describing a Crash Behavior of 2D Plain Weave Fabric Composites. CEAS Aeronautical Journal, 12, 147-171. https://doi.org/10.1007/s13272-020-00488-1 https://link.springer.com/article/10.1007\%2Fs13272-020-00488-1

[28] SIMULIA (2020) Abaqus Documentations. Dassault Systems.

[29] Joosten, M., Dutton, S., Kelly, D. and Thomson, R. (2011) Experimental and Numerical Investigation of the Crushing Response of an Open Section Composite Energy Absorbing Element. Composite Structures, 93, 682-689. https://doi.org/10.1016/j.compstruct.2010.08.011

[30] Chiu, L.N., Falzon, B.G., Boman, R., Chen, B. and Yan, W. (2015) Finite Element Modeling of Composite Structures under Crushing Load. Compoistes Structures, 131, 215-225. https://doi.org/10.1016/j.compstruct.2015.05.008

[31] Esnaola, A., Elguezabal, B., Aurrekkoetxea, J., Gallego, I. and Ulacia, I. (2016) Optimization of the Semi-Hexagonal Geometry of a Composite Crush Structure by Finite Element Analysis. Composites Part B: Engineering, 93, 56-66.

https://doi.org/10.1016/j.compositesb.2016.03.002

[32] Waimer, M., Siemann, M. and Feser, T. (2017) Simulation of CFRP Components Subjected to Dynamic Crash Loads. International Journal of Impact Engineering, 101, 115-131. https://doi.org/10.1016/j.ijimpeng.2016.11.011 